\title{
The Moon at thermal infrared wavelengths: a benchmark for asteroid thermal models
}

\author{
T. G. Müller ${ }^{1}$, M. Burgdorf ${ }^{2}$, V. Alí-Lagoa ${ }^{1}$, S. A. Buehler ${ }^{2}$, and M. Prange ${ }^{2,3}$ \\ ${ }^{1}$ Max-Planck-Institut für extraterrestrische Physik, Giessenbachstraße, Postfach 1312, 85741 Garching, Germany \\ e-mail: tmueller@mpe.mpg.de \\ ${ }^{2}$ Meteorologisches Institut, Centrum für Erdsystem- und Nachhaltigkeitsforschung (CEN), Universität Hamburg, Bundesstrasse 55, \\ 20146 Hamburg, Germany \\ ${ }^{3}$ International Max Planck Research School on Earth System Modelling (IMPRS-ESM), Bundesstraße 53, 20146 Hamburg, \\ Germany
}

Received 20 November 2020 / Accepted 2 March 2021

\begin{abstract}
Thermal-infrared measurements of asteroids, satellites, and distant minor bodies are crucial for deriving the objects' sizes, albedos, and in some cases, also the thermophysical properties of the surface material. Depending on the available measurements and auxiliary data, such as visual light curves, spin and shape information, or direct size measurements from occultations or high-resolution imaging techniques, a range of simple to complex thermal models are applied to achieve specific science goals. However, testing these models is often a difficult process and the uncertainties of the derived parameters are not easy to estimate. Here, we make an attempt to verify a widely accepted thermophysical model (TPM) against unique thermal infrared (IR), full-disk, and well-calibrated measurements of the Moon. The data were obtained by the High-resolution InfraRed Sounder (HIRS) instruments on board a fleet of Earth weather satellites that serendipitously scan the surface of the Moon. We found 22 Moon intrusions, taken in 19 channels between $3.75 \mu \mathrm{m}$ and $15.0 \mu \mathrm{m}$, and over a wide phase angle range from $-73.1^{\circ}$ (waxing Moon) to $+73.8^{\circ}$ (waning Moon). These measurements include the entire Moon in a single pixel, seen almost simultaneously in all bands. The HIRS filters are narrow and outside the wavelength regime of the Christiansen feature. The similarity between these Moon data and typical asteroid spectral-IR energy distributions allows us to benchmark the TPM concepts and to point out problematic aspects. The TPM predictions match the HIRS measurements within 5\% ( $10 \%$ at the shortest wavelengths below $5 \mu \mathrm{m}$ ) when using the Moon's known properties (size, shape, spin, albedo, thermal inertia, roughness) in combination with a newly established wavelength-dependent hemispherical emissivity. In the 5-7.5 $\mu \mathrm{m}$ and in the 9.5$11 \mu \mathrm{m}$ ranges, the global emissivity model deviates considerably from the known lunar sample spectra. Our findings will influence radiometric studies of near-Earth and main-belt asteroids in cases where only short-wavelength data (from e.g., NEOWISE, the warm Spitzer mission, or ground-based $M$-band measurements) are available. The new, full-disk IR Moon model will also be used for the calibration of IR instrumentation on interplanetary missions (e.g., for Hayabusa-2) and weather satellites.
\end{abstract}

Key words. Moon - minor planets, asteroids: general - radiation mechanisms: thermal - techniques: photometric infrared: planetary systems

\section{Introduction}

Thermophysical modeling techniques are widely used to derive radiometric properties of asteroids (e.g., Delbo et al. 2015) and more distant bodies (e.g., Müller et al. 2020). Most of the radiometric studies are based on infrared (IR) measurements taken close to the objects' thermal emission peak: IRAS (Tedesco et al. 2002a) at 12, 25, 60, and $100 \mu \mathrm{m}$, MSX (Tedesco et al. 2002b) at $4.29,4.35,8.28,12.13,14.65$, and $21.3 \mu \mathrm{m}$, AKARI-IRC (Usui et al. 2011, 2013) at 9 and $18 \mu \mathrm{m}$, or WISE/NEOWISE (Mainzer et al. 2011, 2016) at 11 and $22 \mu \mathrm{m}$. For more distant, colder Centaurs or trans-Neptunian objects, key studies used data from Spitzer-MIPS at 24 and $70 \mu \mathrm{m}$ (Stansberry et al. 2008), or from Herschel-PACS at 70, 100, and $160 \mu \mathrm{m}$ (Müller et al. 2020).

A comparison between radiometric sizes and true sizes (from occultations, direct imaging, or in-situ studies) shows an excellent agreement (e.g., Harris \& Lagerros 2002; Usui et al. 2014; Mainzer et al. 2015; Ortiz et al. 2020, and references therein). Deviating radiometric sizes are typically attributed to poor spin-shape information, low-quality or single-epoch thermal observations, or a combination of these aspects.
Recently, more and more IR data of asteroids at shorter wavelengths (far away from the thermal emission peak) have become available: NEOWISE W1 and W2 bands at 3.4 and $4.6 \mu \mathrm{m}$ after the end of the cryogenic mission phase (Mainzer et al. 2014), Spitzer-IRAC at 3.6 and $4.5 \mu \mathrm{m}$ warm mission (2009-2020) (Mahoney et al. 2010), or ground-based observations up to about $5 \mu \mathrm{m}$, for example, using SpeX at NASA's Infrared Telescope Facility (Moskovitz et al. 2017). These short-wavelengths measurements are often focused on near-Earth objects and smaller main-belt asteroids with the goal to obtain the fundamental object properties. However, the radiometric model techniques are not well tested below $10 \mu \mathrm{m}$.

In general, there are no benchmark targets with consistently high-quality disk-integrated thermal measurements over a wide range of wavelengths and phase angles. Either the few objects with accurate or in-situ physical properties are too bright for the IR instruments or the disk-integrated thermal IR data available for those targets are insufficient to independently tackle TPM validation over a wide range of observational configurations and its large model parameter space (e.g., the Hayabusa mission target 25143 Itokawa). Our Moon has been an important 
ground-truth reference in terms of reproducing instantaneous surface temperatures. However, a systematic comparison with asteroid thermophysical studies based on non-resolved data has been more difficult due to instrument saturation problems or the predominance of disk-resolved data that cover only part of the Moon.

For example, the infrared radiometer Diviner (Paige et al. 2010) on board NASA's Lunar Reconnaissance Orbiter (LRO) obtained large amounts of IR measurements and was able to create temperature maps of the Moon's surface. However, a direct comparison between Diviner products and TPM predictions would be restricted to very limited phase angle and wavelength coverage $^{1}$. Furthermore, with the Diviner data it would not be possible to test our TPM over typical asteroid phase angles and in the short-wavelength thermal regime below $7.5 \mu \mathrm{m}$.

Here, we present a unique data set of full-disk Moon measurements in the wavelength range between 3.75 and $15 \mu \mathrm{m}$, obtained by a fleet of weather satellites, each carrying a High Resolution Infrared Radiation Sounder (HIRS) instrument (Sect. 2). We interpret these measurements with a thermophysical model (TPM), which is widely used in the context of minor body studies (Sect. 3). The comparison between our TPM predictions and the HIRS measurements are shown in Sect. 4. The discussion, along with several potential applications of our Moon model, is presented in Sect. 5, followed by our conclusions in Sect. 6.

\section{Disk-integrated thermal-IR measurements of the Moon}

We carried out our investigations with data from HIRS ${ }^{2}$ instruments, which are scanning radiometers that perform operational atmospheric sounding. They are part of the TOVS sounding instrument suite (TIROS ${ }^{3}$ Operational Vertical Sounder) and have evolved up to HIRS/4. In the course of this evolution, the diameter of its field of view (FOV) decreased from $1.4^{\circ}$ to $0.7^{\circ 4}$. HIRS has 19 infrared channels $(3.8-15 \mu \mathrm{m})$ and one visible channel, which is not relevant for our study. The long-wavelength (LW, ch01-12) and short-wavelength (SW, ch13-ch19) channels have different optical paths. There is a displacement of the channels perpendicular to the scan direction. This displacement is different for $\mathrm{LW}$ and $\mathrm{SW}$, but in either case, it is proportional to wavelength (Burgdorf et al. 2020). All channels, therefore, have slightly different view directions, which might sometimes result in the Moon not being fully included in the FoV of all LW or SW channels above or below a certain wavelength.

The two point IR calibration of HIRS is provided by programmed views of two radiometric targets: the warm target, mounted on the instrument baseplate, and a view of deep space (DSV). Each view takes $6.4 \mathrm{sec}$, including the time required to bring the scanning mirror into position. Data from these views provide sensitivity calibrations for each channel at $256 \mathrm{sec}$ intervals. The deep-space view points at a direction close to the orbital axis of the satellite, that is, near the celestial equator. This means that occasionally the Moon appears in the DSV

\footnotetext{
1 In the thermal IR, Diviner has three narrow-band mineralogy channels at $7.8,8.2$, and $8.6 \mu \mathrm{m}$ and four broad-band thermal channels covering the $12.5-200 \mu \mathrm{m}$ range.

2 High-resolution InfraRed Sounder.

3 Television InfraRed Observation Satellite.

4 This decrease reduces the instantaneous FOV size from 20 to $10 \mathrm{~km}$ at the sub-satellite point. The scanning technique, however, remained the same with steps of $26 \mathrm{~km}$ cross-track and $42 \mathrm{~km}$ along-track.
}
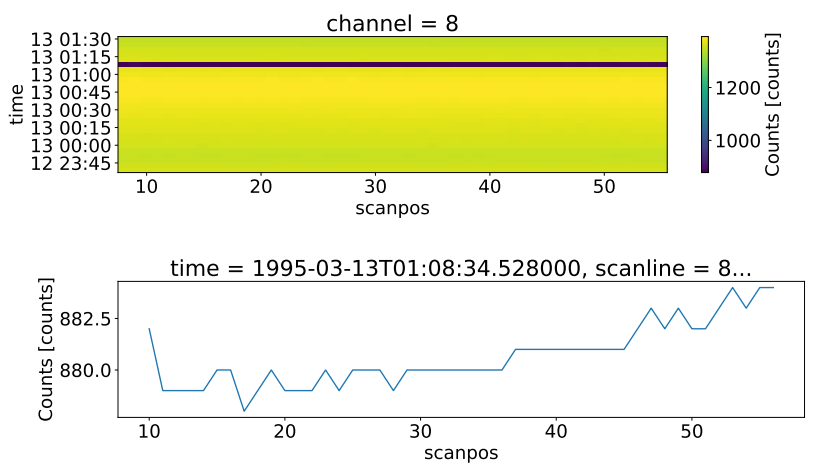

Fig. 1. Signal from channel 8 of HIRS/2 on NOAA-14 while viewing deep space during one complete orbit on March 12-13, 1995 (top). Here, "scanpos" is equivalent to "sample"; all 56 samples of one calibration sequence are taken within $6.4 \mathrm{sec}$. As HIRS gives fewer counts for stronger flux, any intrusion of the Moon in the field of view is easily recognizable by the exceptionally low number of counts. The number of counts from the scan with the Moon in the FOV is plotted in the bottom panel, where it is possible to see that the Moon was fully included in the FOV until scanpos 33. Then it began to slowly move out. At scanpos 10 , the scanning mirror had not yet reached its final position and, therefore, the Moon was not fully included in the FOV.

at the time of the calibration. Its presence corrupts the signal, which normally corresponds to zero flux. In most cases, the signal from the Moon changes over the $6.4 \mathrm{sec}$ while the instrument is viewing space because the Moon is moving in or out of the FOV, but when its signal is constant, the Moon must be fully included in the FOV and none of its flux is lost. Such events were tracked down with the help of STAR ICVS ${ }^{5}$ (Integrated Calibration/Validation System Long-Term Monitoring) and identified in the level $1 \mathrm{~b}$ data from eight different satellites in the NOAA CLASS (Comprehensive Large Array-data Stewardship System) archive (see Fig. 1). The HIRS Level 1b datasets provide raw instrument counts. Once we found a suitable Moon intrusion in the DSV, we used the observations of the warm target and of the DSV before and after for the IR calibration of HIRS.

The noise of the measurements was calculated directly from the distribution of the counts in each channel. The bottom panel of Fig. 1 demonstrates the impact of digitization on the $\mathrm{PDF}^{6}$ shape. On top of the pure random variations of the counts, there is also the structured effect of short-term temperature changes of a baffle contributing to the counts from the receiver (Labrot et al. 2019). Developing a self-emission model for HIRS in order to correct for these temperature changes, however, is hardly worthwhile in light of the small number of Moon intrusions we identified. The additional uncertainty caused by this effect was instead estimated from the difference of the flux values measured at very similar phase angles of the Moon and from the scatter of the counts in the DSV calibration measurements when the Moon was absent. While the size of the independent noise is usually negligible, the temperature changes lead to an uncertainty of some $2 \mathrm{~K}$ in the measured brightness temperatures.

There are several common effects that limit the accuracy of the measurements. Band corrections for each IR channel are used to modify the temperature of the warm target as measured with the platinum resistance thermometers to give an effective temperature. The effective temperature is for use in the Planck function so that the correct radiance is obtained with the

\footnotetext{
5 https://www.star.nesdis.noaa.gov/icvs/index.php 6 Probability Density Function.
} 
T. G. Müller et al.: Benchmarking the asteroid TPM against the Moon

Table 1. Overview of HIRS measurements where the Moon was completely in the FOV.

\begin{tabular}{|c|c|c|c|c|c|c|c|}
\hline Satellite & Instr. & $\begin{array}{r}\text { Julian } \\
\text { date } \\
\end{array}$ & $\begin{array}{r}\text { Date } \\
\text { YYYY-MM-DD } \\
\end{array}$ & $\begin{array}{r}\text { Time } \\
\text { HH:MM }\end{array}$ & $\begin{array}{r}\text { Longitude } \\
{\left[{ }^{\circ}\right]} \\
\end{array}$ & $\begin{array}{r}\text { Latitude } \\
{\left[{ }^{\circ}\right]}\end{array}$ & $\begin{array}{r}\text { Altitude } \\
{[\mathrm{km}]}\end{array}$ \\
\hline JOAA-11 & IIRS2 & 2449317.23542 & $1993-11-25$ & $17: 39$ & +157.5 & -11.95 & 852 \\
\hline JOAA-11 & IIRS2 & 2448668.32917 & $1992-02-15$ & $19: 54$ & -66.4 & -43.19 & 845 \\
\hline NOAA-11 & HIRS2 & 2448222.71111 & $1990-11-27$ & 05:04 & -38.2 & +23.43 & 850 \\
\hline NOAA-11 & HIRS2 & 2447602.64653 & $1989-03-17$ & $03: 31$ & +166.6 & -56.45 & 887 \\
\hline NOAA-14 & HIRS2 & 2451648.95139 & 2000-04-14 & $10: 50$ & -105.3 & -14.38 & 856 \\
\hline NOAA-14 & HIRS2 & 2450791.41111 & $1997-12-08$ & $21: 52$ & +73.3 & +24.68 & 849 \\
\hline NOAA-14 & HIRS2 & 2450614.71181 & $1997-06-15$ & $05: 05$ & -31.8 & +48.97 & 867 \\
\hline NOAA-14 & HIRS2 & 2450379.52083 & $1996-10-23$ & $00: 30$ & -167.2 & +47.91 & 867 \\
\hline NOAA-14 & HIRS2 & 2450232.37361 & $1996-05-28$ & $20: 58$ & -120.1 & +56.81 & 866 \\
\hline NOAA-14 & HIRS2 & 2450054.80069 & $1995-12-03$ & $07: 13$ & +99.8 & -8.31 & 858 \\
\hline NOAA- $15^{(a)}$ & HIRS3 & 2458831.90792 & 2019-12-14 & 09:47 & +151.3 & -53.35 & 832 \\
\hline NOAA- $15^{(b)}$ & HIRS3 & 2458476.98889 & $2018-12-24$ & $11: 44$ & +114.1 & -43.93 & 822 \\
\hline NOAA- $17^{(c)}$ & HIRS3 & 2452663.55486 & $2003-01-24$ & $01: 19$ & -56.0 & +44.19 & 813 \\
\hline NOAA-17 ${ }^{(d)}$ & HIRS3 & 2452543.79236 & 2002-09-26 & 07:01 & +39.8 & -33.81 & 836 \\
\hline NOAA-18 & HIRS4 & 2458449.24931 & $2018-11-26$ & $17: 59$ & +41.7 & -41.40 & 865 \\
\hline NOAA-18 & HIRS4 & 2458210.89375 & 2018-04-02 & $09: 27$ & +53.6 & +80.63 & 868 \\
\hline NOAA-18 & HIRS4 & 2455634.93889 & $2011-03-14$ & $10: 32$ & -134.8 & -46.89 & 882 \\
\hline NOAA-19 & HIRS4 & 2458090.03403 & 2017-12-02 & $12: 49$ & +44.5 & -16.96 & 869 \\
\hline NOAA-19 $9^{(e)}$ & HIRS4 & 2455990.71324 & 2012-03-04 & 05:07 & +132.2 & -34.69 & 858 \\
\hline MetOp-A & HIRS4 & 2455882.48750 & $2011-11-16$ & $23: 42$ & -31.7 & -11.60 & 825 \\
\hline MetOp-B & HIRS4 & 2458685.83125 & 2019-07-21 & $07: 57$ & +94.2 & +80.74 & 833 \\
\hline MetOp-B & HIRS4 & 2457060.71667 & $2015-02-07$ & $05: 12$ & +70.6 & +33.23 & 824 \\
\hline
\end{tabular}

Notes. The satellite longitude (positive values: east, negative values: west), latitude (positive values: north, negative values: south), and altitude values (in kilometers above the Earth's surface) are needed to calculate the correct viewing geometry for the Moon (distance, phase angle, and apparent diameter). ${ }^{(a)}$ Moon was only fully included in the FOV in ch18 and ch19. ${ }^{(b)}$ Possibly touching edge of ch08-ch12 FOV. ${ }^{(c)}$ Possibly touching edge of ch08-ch19 FOV. ${ }^{(d)}$ Possibly touching edge of ch01-ch19 FOV. ${ }^{(e)}$ Moon was only in ch18 and ch19 in the FOV.

central wavelengths (see Labrot et al. 2019, and the corresponding software documentation ${ }^{7}$ ).

The spectral response functions for each HIRS channel had to be optimized to generate a more consistent set of observations (Chen et al. 2013). Shift values were therefore used as provided by E. Borbas ${ }^{8}$.

We assumed that radiance can be related to counts through a linear equation. This assumption can be made because the nonlinearity term in the HIRS radiometric calibration was found to be much smaller in flight than the pre-launch value (Chen \& Cao 2012), and the ATOVS ${ }^{9}$ and AVHRR ${ }^{10}$ Pre-processing Package (AAPP) does not perform a non-linearity correction either.

The diameter of the FOV was assumed to be $1.4^{\circ}$ for HIRS/2, $1.3^{\circ}$ for $\mathrm{HIRS} / 3$, and $0.7^{\circ}$ for HIRS $/ 4$ according to OSCAR (Observing Systems Capability Analysis and Review Tool) ${ }^{11}$. These numbers were verified by comparing the flux values measured with different satellites at very similar phase angles of the Moon. The uncertainty of the diameter of the FOV causes an uncertainty of the measured fluxes of at most a few percent. All channels $1-12$ or 13-19 of a given satellite are affected in the same way.

In summary, our processing of the raw data from the Moon intrusions used the same method as AAPP, namely: using a

\footnotetext{
7 https://www.nwpsaf.eu/site/software/aapp/ documentation/

8 https://www.nwpsaf.eu/site/software/rttov/download/ coefficients/spectral-response-functions/

9 Advanced TIROS Operational Vertical Sounder.

${ }^{10}$ Advanced Very High Resolution Radiometer.

11 http://www. wmo-sat.info/oscar/
}

two-point calibration interpolating between the signals from the warm (between 283.72 and $285.97 \mathrm{~K}$, depending on instrument setting) and the cold target (space background), but without taking the changing flux contributions from the baffle into account (see also Burgdorf et al. 2020). Table 1 lists the events when the Moon was completely in the FOV (at least for a subset of channels). Table 2 summarizes the observing geometry as seen from the satellites, together with apparent Moon properties.

The phase angles of the Moon and its apparent diameter (in Table 2) were calculated with the JPL HORIZONS system $^{12}$. It requires knowledge of the Nadir Position, which is included in the level $1 \mathrm{~b}$ data. The altitude of the orbit changes just slightly during the mission and is available for each satellite from OSCAR. Date and time are given for the mid-point of the Moon scan. The central wavelength $\lambda_{\text {chxx }}$ for each infrared channel (and instrument), with " $\mathrm{xx}$ " ranging from 01 to 19 , are given at the project web page ${ }^{13}$. Following the above-described procedure, we extracted the counts from the warm and cold targets closest to the Moon intrusion. Count errors are a combination of standard deviation of the counts and digitization errors. Then the warm load blackbody (BB) temperatures (five temperatures for HIRS/2 and HIRS/3 and six temperatures for HIRS/4) were converted to $\mathrm{BB}$ radiances (Planck function applied to $\mathrm{BB}$ temperatures for wavenumbers ${ }^{14}$ ). We used the shifted relative spectral response functions and applied the band-correction

\footnotetext{
12 https://ssd.jpl.nasa.gov/?horizons

13 https://www.nwpsaf.eu/site/software/rttov/download/ coefficients/spectral-response-functions/

14 https://www.nwpsaf.eu/site/software/rttov/download/ coefficients/spectral-response-functions/
} 
Table 2. Overview of the Moon geometry during the HIRS measurements.

\begin{tabular}{crrrrrr}
\hline \hline $\begin{array}{c}\text { Date \& } \\
\text { time }\end{array}$ & $\begin{array}{r}\text { APmag } \\
{[\mathrm{mag}]}\end{array}$ & $\begin{array}{r}\Delta \\
{[\mathrm{km}]}\end{array}$ & $\begin{array}{r}\alpha \\
{\left[{ }^{\circ}\right]}\end{array}$ & $\begin{array}{r}\text { Diameter } \\
{\left[{ }^{\prime \prime}\right] \&[\mathrm{sr}]}\end{array}$ & $\begin{array}{r}\text { Ob-lon } \\
{\left[{ }^{\circ}\right]}\end{array}$ & $\begin{array}{r}\text { Ob-lat } \\
{\left[{ }^{\circ}\right]}\end{array}$ \\
\hline $1993-11-2517: 39$ & -11.57 & $4.06832 \mathrm{E}+05$ & -40.1 & $1761.7375 .72946 \mathrm{e}-05$ & 359.1 & -4.8 \\
$1992-02-1519: 54$ & -11.96 & $3.62777 \mathrm{E}+05$ & -34.6 & $1975.6837 .20553 \mathrm{e}-05$ & 357.5 & +0.6 \\
$1990-11-2705: 04$ & -10.83 & $3.80571 \mathrm{E}+05$ & -70.8 & $1883.3056 .54746 \mathrm{e}-05$ & 351.2 & -5.4 \\
$1989-03-1703: 31$ & -11.11 & $3.98021 \mathrm{E}+05$ & -57.5 & $1800.7375 .98594 \mathrm{e}-05$ & 6.8 & -4.9 \\
$2000-04-1410: 50$ & -11.31 & $3.79167 \mathrm{E}+05$ & -53.7 & $1890.2796 .59604 \mathrm{e}-05$ & 2.9 & -3.3 \\
$1997-12-0821: 52$ & -10.93 & $3.71395 \mathrm{E}+05$ & -69.2 & $1929.8376 .87500 \mathrm{e}-05$ & 358.7 & +2.7 \\
$1997-06-1505: 05$ & -10.74 & $4.00922 \mathrm{E}+05$ & -68.0 & $1787.7085 .89963 \mathrm{e}-05$ & 355.4 & -1.5 \\
$1996-10-2300: 30$ & -11.58 & $3.70828 \mathrm{E}+05$ & -46.3 & $1932.7856 .89602 \mathrm{e}-05$ & 2.1 & -1.8 \\
$1996-05-28 ~ 20: 58$ & -11.32 & $3.86040 \mathrm{E}+05$ & -51.1 & $1856.6266 .36327 \mathrm{e}-05$ & 354.0 & +0.6 \\
$1995-12-0307: 13$ & -11.60 & $3.97263 \mathrm{E}+05$ & -40.8 & $1804.1726 .00880 \mathrm{e}-05$ & 6.8 & +0.7 \\
$2019-12-1409: 47$ & -12.06 & $3.77946 \mathrm{E}+05$ & 28.0 & $1896.3846 .63883 \mathrm{e}-05$ & 356.5 & -2.2 \\
$2018-12-2411: 44$ & -12.23 & $3.63363 \mathrm{E}+05$ & 24.8 & $1972.4987 .18232 \mathrm{e}-05$ & 0.4 & -0.8 \\
$2003-01-2401: 19$ & -10.79 & $3.71946 \mathrm{E}+05$ & 73.8 & $1926.9786 .85465 \mathrm{e}-05$ & 0.7 & -4.7 \\
$2002-09-2607: 01$ & -11.26 & $4.04338 \mathrm{E}+05$ & 50.5 & $1772.6045 .80036 \mathrm{e}-05$ & 354.8 & +1.3 \\
$2018-11-2617: 59$ & -11.58 & $3.68917 \mathrm{E}+05$ & 47.5 & $1942.7996 .96767 \mathrm{e}-05$ & 0.5 & +0.0 \\
$2018-04-0209: 27$ & -12.07 & $3.88859 \mathrm{E}+05$ & 23.8 & $1843.1646 .27133 \mathrm{e}-05$ & 5.2 & -5.6 \\
$2011-03-1410: 32$ & -10.74 & $3.81174 \mathrm{E}+05$ & -73.1 & $1880.3276 .52677 \mathrm{e}-05$ & 351.2 & +0.7 \\
$2017-12-0212: 49$ & -12.47 & $3.63073 \mathrm{E}+05$ & -15.6 & $1974.0717 .19378 \mathrm{e}-05$ & 357.5 & +6.5 \\
$2012-03-0405: 07$ & -11.30 & $3.88740 \mathrm{E}+05$ & -53.2 & $1843.7316 .27529 \mathrm{e}-05$ & 353.9 & +3.7 \\
$2011-11-1623: 42$ & -10.79 & $3.87761 \mathrm{E}+05$ & 70.6 & $1848.3846 .30690 \mathrm{e}-05$ & 354.1 & +4.8 \\
$2019-07-2107: 57$ & -11.27 & $4.07689 \mathrm{E}+05$ & 48.7 & $1758.0355 .70541 \mathrm{e}-05$ & 357.9 & +6.8 \\
$2015-02-0705: 12$ & -11.71 & $4.08035 \mathrm{E}+05$ & 34.7 & $1756.5435 .69573 \mathrm{e}-05$ & 357.3 & +2.9 \\
\hline
\end{tabular}

Notes. APmag is the apparent visual magnitude of the Moon; $\Delta$ is the satellite-Moon distance in kilometer; $\alpha$ the phase angle (Sun-MoonSatellite): positive values if the Moon is leading the Sun and negative values when the Moon is trailing the Sun; the diameter of the Moon's full disk is given via the equatorial angular width (in arcsec and steradian), Ob-lon and Ob-lat give the apparent sub-observer longitude and latitude values. The sub-Solar longitude and latitude is not listed, but the sub-Solar latitude varies only between -1.6 and $+1.5^{\circ}$.

coefficients (correction coefficients from version 31 of the file "calcoef.dat" in AAPP) to the central wavenumbers. This radiance divided by the difference BB - DSV gave a slope. The radiance of the Moon (in $\mathrm{MJy} \mathrm{sr}^{-1}$ ) was then calculated with the two-point calibration using the slope and the difference Moon - DSV. This value is divided by the fraction of the FOV filled by the Moon and the beam efficiency (see Koenig 1980 and the User's Guide ${ }^{15}$ ). Its $\sigma$ was calculated with the error propagation from the counts, assuming that the error of the BB Temp is zero.

For the direct comparison with TPM techniques, we convert the calibrated Moon radiances (in $\mathrm{MJy} \mathrm{sr}^{-1}$ ) into (diskintegrated) flux densities (in Jy) by multiplying the radiances with the apparent solid angle of the Moon at the times of the observations (column "diameter" in Table 2). We use the following conventions for the Moon's phase angles: The phase angles for the waning Moon (indicated by "L" for "leading the Sun" in the JPL HORIZONS system) have positive values, the phase angles for the waxing Moon (indicated by "T" for "trailing the Sun" in the JPL HORIZONS system) have negative values, that is, the first quarter waxing Moon has $\alpha=-90^{\circ}$ and the third quarter waning Moon has $\alpha=+90^{\circ}$. Here, the leading or trailing of the Sun is related to an observer placed on the given satellite longitude, latitude, and altitude (see Table 1) and in consideration of the Earth's rotational direction.

The results from all 22 intrusions of the Moon in the DSV that we identified in the raw data from various satellites are compiled in Tables A.1-A.3 (calibrated radiances and brightness temperatures), and in Tables A.4 and A.5 (flux densities). The

\footnotetext{
15 https://archive.org/details/noaa-klm-guide/page/n5/ mode/2up
}

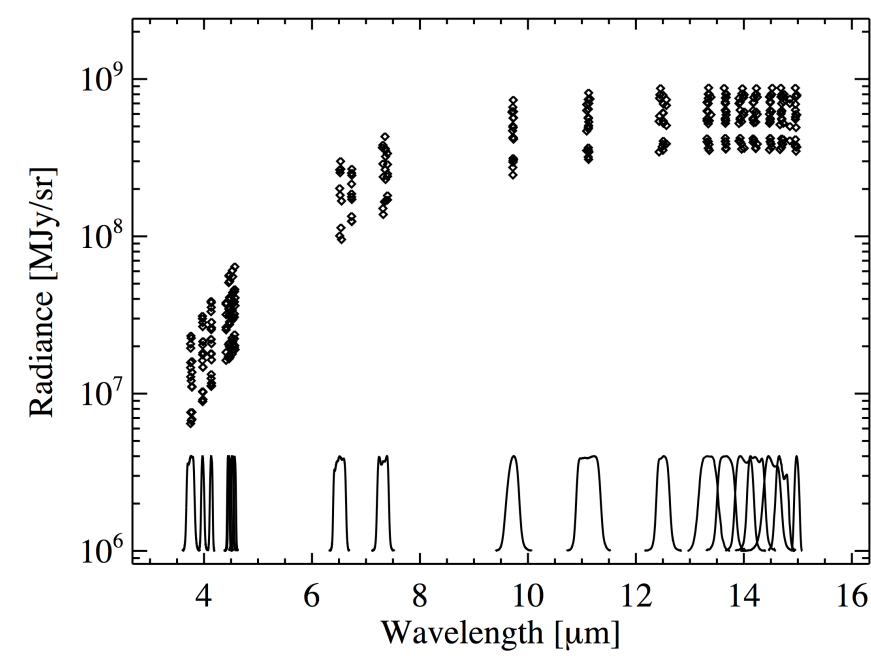

Fig. 2. Calibrated Moon radiance values for the 19 HIRS thermal IR filters for all 22 observing epochs, as a function of wavelengths. The arbitrarily-scaled filter curves (NOAA-18/HIRS/4) are overplotted. The peak transmission of these narrow filters is always close to 1 . The variation in radiance at a given wavelength is mainly related to the different heliocentric distances of the Moon (ranging from $r=0.985$ to $1.018 \mathrm{au}$ ) and the large range of phase angles (from $-73.1^{\circ}$ to $+73.8^{\circ}$ ).

random measurement errors in radiance values, brightness temperatures, and flux densities are usually well below $1 \%$, and in very few cases close to $2 \%$. These errors are based on the scatter of multiple samples used for each radiance determination. The calibrated Moon radiances are shown in Figs. 2 and 3. 


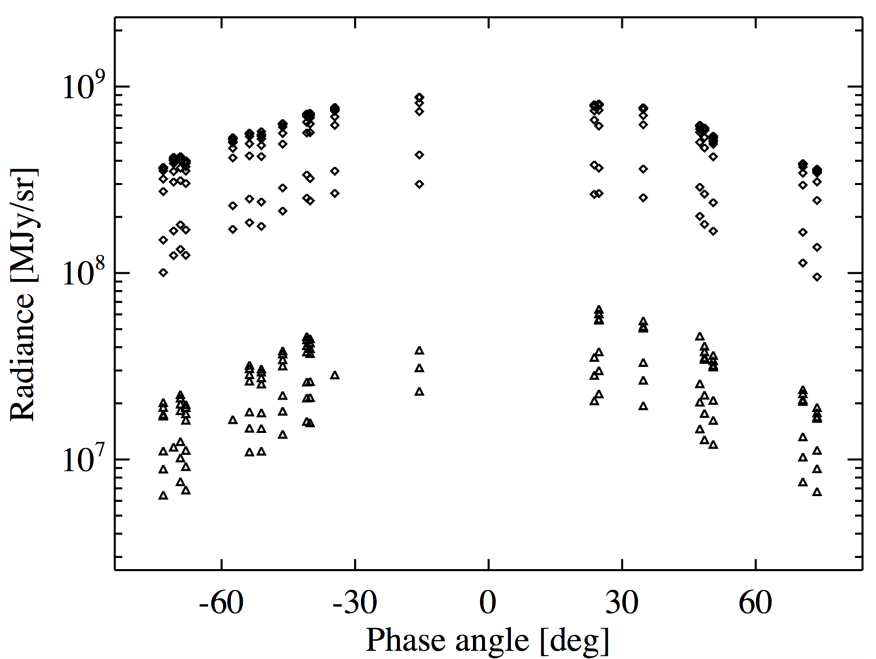

Fig. 3. Calibrated Moon radiances for the 19 HIRS thermal $I R$ filters for all 22 observing epochs, as a function of phase angle. The data at the top (diamonds) are from the long-wavelength channels 1-12 (14.9$6.7 \mu \mathrm{m}$ ). The lower data points (triangles) are from the short-wavelength channels 13-19 $(4.6-3.7 \mu \mathrm{m})$. The variation in radiance at a given phase angle is mainly related to the different wavelengths (from below $4 \mu \mathrm{m}$ to almost $15 \mu \mathrm{m}$ ) and heliocentric distances of the Moon (ranging from $r=0.985$ to $1.018 \mathrm{au})$

\section{TPM of the Moon}

\subsection{TPM}

The interpretation of the measured fluxes and the comparison with model fluxes is done via a thermophysical model (TPM) code developed by Lagerros (1996, 1997, 1998), Müller \& Lagerros (1998, 2002), and Müller (2002). This model was used over the last two decades for near-Earth asteroids (NEAs; e.g., Müller et al. 2014c), main-belt asteroids (MBAs; e.g., Alí-Lagoa et al. 2020), satellites (e.g., Detre et al. 2020), or trans-Neptunian objects (TNOs; e.g., Müller et al. 2020). It was extensively tested and validated against objects and object properties that are known from direct measurements (i.e., occultations, radar, or direct imaging) or from interplanetary mission rendezvous and flybys (e.g., Müller et al. 2014a,b). Between 2016 and 2019, extensive efforts were undertaken to compare quantities derived from TPM techniques with other methods and to constrain the accuracy of TPM properties (Müller et al. 2018). Overall, the TPM produced very high-quality diameters and albedos and consistent thermal properties in cases where the available thermal data have good quality, cover wide spans of time, wavelengths, and phase angles, which is why the new lunar HIRS measurements are so valuable for our purposes.

The TPM predicts the thermal emission of atmosphereless bodies in the infrared to microwave regime. In the TPM the reflected sunlight can be estimated by using Lambert's scattering law, but the calculations have not been optimized nor tested in the transition region between reflected light and thermal emission where non-linear effects are involved. The location and the width of the transition region depends on the object's heliocentric distance, albedo, and thermal properties. For the Moon and near-Earth asteroids (NEA), the thermal emission starts to dominate beyond $3 \mu \mathrm{m}$ (see Fig. 4) for main-belt asteroids the transition is located between 4 and $6 \mu \mathrm{m}$; whereas for more distant bodies, such as trans-Neptunian objects, the transition happens at around $10 \mu \mathrm{m}$ or longer wavelengths. The TPM

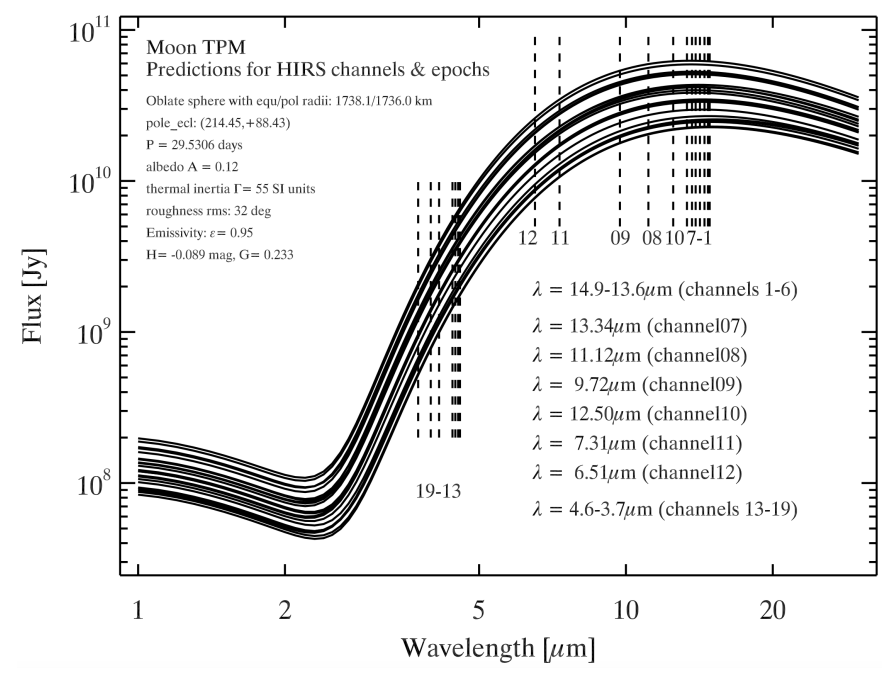

Fig. 4. TPM predictions of the disk-integrated flux densities as a function of wavelengths for all 22 observing epochs. The central positions of the HIRS IR bands are indicated by dotted lines. The variation in absolute flux density is mainly related to the changing phase angles and, in second order, to the small changes in heliocentric distance and observerMoon distance. The thermal emission peak lies between 10 and $20 \mu \mathrm{m}$, the transition between reflected sunlight and thermal emission is located between 2 and $3 \mu \mathrm{m}$. A constant hemispherical spectral emissivity of 0.95 was assumed for these predictions.

can handle complex object shapes and it takes the spin state into account. The heat conduction into the surface is calculated for each surface facet. The surface roughness is modeled by hemispherical segments and controlled by specifying the root-mean-square (rms) of surface slopes (see also Davidsson et al. 2015). When calculating the directional- and wavelengthdependent emissivity, the TPM considers sub-surface scattering processes.

The TPM can be used for radiometric studies to derive an object's size and albedo, as well as, in some cases, thermal, shape, or rotational properties via the interpretation of disk-integrated thermal measurements. For objects with known properties, such as for the Moon or asteroids with in-situ studies, the TPM can make predictions of the object's surface temperatures, disk-integrated flux densities in the thermal wavelength regime, or thermal lightcurves for aspherical bodies or objects with albedo variations. These predictions can be used for a direct comparison with thermal measurements, as here for the Moon or for calibration purposes (see e.g., Müller et al. 2014a).

The prediction of the thermal emission of the Moon can be described in three steps: (i) the temperature of each surface element over the entire Moon has to be estimated; (ii) the intensity $I_{\lambda}$ of each surface element in the direction towards the observer has to be calculated; (iii) the disk-integrated flux is then determined as $F_{\lambda}=\frac{1}{\Delta^{2}} \oint I_{\lambda}(S) \mu \mathrm{d} S$, where $\Delta$ is the observer's distance, $\mathrm{d} S$ is the surface element, and $I_{\lambda}(\mathrm{S})$ is the corresponding intensity towards the observer, and $\mu$ is the direction cosine, projecting the surface element towards the observer. In the TPM, the $I_{\lambda}$ can be described as $I_{\lambda}=\epsilon_{\mathrm{d}} \frac{B_{\lambda}(\gamma T)}{\pi}+I_{\mathrm{sc}}+I_{\text {ref }}$, where $\mathrm{T}$ is the surface temperature and $B_{\lambda}$ is the Planck function. $\gamma$ is the beaming function, $\epsilon_{\mathrm{d}}$ is the direction and wavelength-dependent emissivity ( $\epsilon_{\mathrm{d}} / \pi$ is the hemispherical spectral emissivity), $I_{\mathrm{sc}}$ is the multiple scattered radiation, and $I_{\text {ref }}$ is the reflected solar radiation. For the temperature calculation, the Solar constant $\left(1361 \mathrm{~W} \mathrm{~m}^{-2}\right.$ at 1 au from the Sun; Kopp \& Lean 2011), the object's heliocentric 
distance, $r$, and the surface albedo, A, are needed. We estimated that the Earth's contribution to the energy balance of the Moon is negligible: the thermal emission of the Earth is about $240 \mathrm{~W} \mathrm{~m}^{-2}$ (in all directions, averaged over several years) ${ }^{16}$. At the Moon distance, the Earth's contribution has to be scaled down by $(6371 \mathrm{~km})^{2} /(384400 \mathrm{~km})^{2}$, which is less than $0.1 \mathrm{~W} \mathrm{~m}^{-2}$ (see also Glenar et al. 2019).

The thermal emission of an idealized perfectly flat surface deviates from that of a macroscopically rough one due to partial shadowing, the scattering of sunlight, and self-heating. These effects lead to small areas with higher temperatures and more thermal radiation being emitted in the direction back towards the Sun, known as the thermal-IR beaming effect. There are different ways of describing and implementing surface roughness concepts in TPMs (Davidsson et al. 2015). The most common way of expressing the thermally-relevant level of surface roughness is by specifying the rms slope (see definition in Spencer 1990). We use a roughness implementation via hemispherical segmented craters where the depth-to-diameter ratio and the surface crater coverage can be modified to simulate different rms values and to calculate the beaming function, $\gamma$, (Lagerros 1996, 1998). The $\gamma$ values are then used to correct the thermal emission for roughness effects. At the end, the direction and wavelength-dependent emissivity, $\epsilon_{\mathrm{d}}$, is required for the prediction of the final (diskintegrated) flux, $F_{\lambda}$, at a given wavelength (see Lagerros 1996, 1997, 1998; Müller \& Lagerros 1998, 2002; Müller 2002).

The energy balance on the surface is closely related to its albedo and emissivity. It determines the daytime surface temperature of the Moon. Since the Planck function is so strongly non-linear, it is important to mention that the hottest surface regions dominate the disk-integrated emission of an atmosphereless body at short wavelength up to the thermal emission peak. Only at longer wavelengths, beyond the emission peak, the global, disk-averaged object properties are thermally relevant. The nighttime temperatures are tightly connected to the thermal inertia, which is a function of thermal conductivity, density, and heat capacity. However, our HIRS measurements, taken between the first and the third quarter Moon, are all dominated by the emission from the illuminated part of the Moon and the thermal inertia is not important in this case.

\subsection{Relevant Moon properties}

For the Moon, we consider its equatorial radius of $1738.1 \mathrm{~km}$, its polar radius of $1736.0 \mathrm{~km}$, its synodic period of 29.530589 days, and its north pole coordinates with RA $266.86^{\circ}$ and Dec $65.64^{\circ}$ (taken from the "Moon fact sheet"17, Lang (2012), and from the $\left.\mathrm{IAU}^{18}\right)$. The observing epoch and the satellite position, together with the Moon's pole axis, allow us to calculate the sub-solar and sub-spacecraft longitudes and latitudes for each measurement, namely, the true illumination and observing geometry. The sub-solar latitudes for our 22 epochs cover the range from $-1.6^{\circ}$ to $+1.5^{\circ}$, while the sub-observer (spacecraft) latitude spans the range from $-5.6^{\circ}$ to $+6.8^{\circ}$. Hayne et al. (2017) presented the global thermophysical properties of the Moon's regolith fines layer. The diurnally active near-surface layer is about $4-7 \mathrm{~cm}$ thick, with a top-layer thermal conductivity of $7.4 \times 10^{-4} \mathrm{~W} \mathrm{~m}^{-1} \mathrm{~K}^{-1}\left(3.4 \times 10^{-3} \mathrm{~W} \mathrm{~m}^{-1} \mathrm{~K}^{-1}\right.$ at a depth

\footnotetext{
16 https://science-edu.larc.nasa.gov/energy_budget/

17 https://nssdc.gsfc.nasa.gov/planetary/factsheet/ moonfact.html

${ }^{18}$ Celest. Mech. Dyn. Astr; https://doi.org/10.1007/s10569Q10-9320-4
}

of $\approx 1 \mathrm{~m})$ and it has a globally averaged thermal inertia $\Gamma=$ $55 \pm 2 \mathrm{~J} \mathrm{~m}^{-2} \mathrm{~K}^{-1} \mathrm{~s}^{-1 / 2}$ at $273 \mathrm{~K}$ (and for an albedo of 0.12 ). Overall, the regolith fines are very uniform and lack hemispheric or any maria-highlands dichotomy. Only small regions show significant deviations in $\Gamma$ : the interiors of prominent impact craters and specific crater ejecta have $\Gamma$-values close to or above $100 \mathrm{~J} \mathrm{~m}^{-2} \mathrm{~K}^{-1} \mathrm{~s}^{-1 / 2}$ and the lunar cold spots have $\Gamma \leq 50 \mathrm{~J} \mathrm{~m}^{-2} \mathrm{~K}^{-1} \mathrm{~s}^{-1 / 2}$ Bandfield et al. (2014). Measurements at the equator show that the derived thermal inertia of a given area can vary from around $35 \mathrm{~J} \mathrm{~m}^{-2} \mathrm{~K}^{-1} \mathrm{~s}^{-1 / 2}$ at midnight to about $70 \mathrm{~J} \mathrm{~m}^{-2} \mathrm{~K}^{-1} \mathrm{~s}^{-1 / 2}$ at noon due to the temperature dependence of the thermal conductivity and heat capacity. However, for global flux calculations in the HIRS wavelength and phase angle regimes, this temperature dependence of the thermal inertia is not relevant since the observed flux is dominated by the hotter terrains that are still visible.

The lunar average Bond albedo (at normal solar incidence) A is 0.12 (Vasavada et al. 2012). This is in agreement with the mean value of 0.122 found by Saari \& Shorthill (1972). Vasavada et al. (2012) derived a mean albedo of 0.07 for mare and 0.16 for highland surfaces from measurements taken by the Diviner Lunar Radio Experiment. In a NASA summary of the Moon's bulk parameters ${ }^{19}$, the Bond albedo is given by 0.11 and the geometric albedo by 0.12 . The Moon's three-parameter magnitude phase function $\mathrm{H}, G_{1}, G_{2}$ was determined by Muinonen et al. (2010). The absolute ( $V$-band) magnitude $H=-0.154_{+0.118}^{-0.057} \mathrm{mag}$, $G_{1}=0.36_{+0.14}^{-0.12}, G_{2}=0.338_{+0.049}^{-0.052}$ fit the observed reduced magnitudes over a wide phase angle range from 0 to $100^{\circ}$ with a residual $\mathrm{rms}$ of only $0.016 \mathrm{mag}$, including the opposition surge of $0.43 \mathrm{mag}$. The two-parameter $H-G_{12}$ phase function values are $H=-0.124_{+0.022}^{-0.020} \mathrm{mag}, G_{12}=0.358 \pm 0.073$. A simpler Lumme-Bowell fit to the phase function by Bowell et al. (1989) gives $H=-0.089 \mathrm{mag}$ and $G=0.233$. The phase integral $\mathrm{q}$ is $0.43 \pm 0.04$ (Muinonen et al. 2010) or can be determined via $q=0.290+0.684 G=0.45$ (Bowell et al. 1989). The $H-G$, and $q$ values play an important role in the context of radiometric asteroid studies where size and albedo are derived from thermal measurements (see e.g., Delbo et al. 2015). An asteroid's geometric $V$-band albedo $p_{V}$ can be calculated from its diameter $D$ (often derived from occultation measurements or given by radiometric solutions) and its absolute magnitude $H$ via $p_{V}=10^{\left(6.2472-2 A L O G 10(D)-0.4 H_{V}\right)}$. To obtain the correct albedo value for the Moon, we have to use the Moon's size $(3474.8 \mathrm{~km})$, together with the $H_{V}$ magnitude but without the 0.43 mag opposition surge.

The bolometric emissivity $\epsilon$ changes with emission angle and surface roughness effects are also angle sensitive. However, to be able to directly compare this study with the TPM framework used for asteroids, we kept both properties fixed to their average values in our global Moon model. The bolometric infrared emissivity $\epsilon$ (as used for the temperature calculation) was found to be 0.95 , based on spectroscopic studies of lunar materials (Donaldson Hanna et al. 2012) and averaging over wide ranges of emission angles (Bandfield et al. 2015). This is the apparent broadband hemispherical emissivity, originating from average daytime emission phase function measurements.

The hemispherical lunar surface spectral emissivity $\left(\epsilon_{d}\right.$ in the TPM convention) can be assumed to be constant (with typical values of $0.90,0.95,1.00$ ) or it can be calculated from the measured reflectance values listed in the ECOSTRESS

\footnotetext{
19 https://nssdc.gsfc.nasa.gov/planetary/factsheet/ moonfact . html
} 
database $^{20}$ : There are 17 lunar reflectance spectra available, all derived from Apollo Moon samples (Apollo 11, 12, 14, and 16; Salisbury et al. 1997), and covering the wavelength range from 2.079 to $14.011 \mu \mathrm{m}$. They include: (i) Apollo 11, 12 - Maria (lunar oceans): corresponding to "young soil" (darker material); (ii) Apollo 16, (14) - Highlands: corresponding to "old soil" (brighter material); (iii) Apollo 14 - Transitional case. Overall, the emittance (1 - reflectance) spectral properties are dependent of the surface type and show only subtle spectral variations between surfaces of different composition and maturity (e.g., Greenhagen et al. 2010). Only below $6 \mu \mathrm{m}$ do they differ substantially.

There are many studies and discussions in the literature that examine the relevant roughness scales for the Moon and other atmosphereless bodies. Helfenstein \& Shepard (1999) produced digital topographic relief maps from closeup lunar images and measured the surface roughness at $1-\mathrm{cm}$ scale. They found a rms slope close to $10^{\circ}$. But since their image footprints were smaller than one square decimeter, they had no information on the roughness statistics at meter or kilometer scales. Ostro (1993) derived the lunar rms slope to be $\approx 33^{\circ}$. His radar observations were sensitive to spatial scales between the radar wavelength and the spot size of the sub-radar point. Rozitis \& Green (2011) discussed a wide range of lunar roughness studies and applied their model to lunar measurements presented by Saari \& Shorthill (1972). In the summary of their work, they listed lunar surface roughness values between $30^{\circ}$ and $39^{\circ}$, all derived by thermal models. Their own best value is $\approx 32^{\circ}$, inferred from the lunar thermal-IR beaming effect, and in agreement with the radar studies by Ostro (1993). Rosenburg et al. (2011) quantified the surface roughness properties of the Moon based on data from the Lunar Orbiter Laser Altimeter (LOLA), carried on the LRO. Using baselines ranging from $\approx 17 \mathrm{~m}$ to several kilometers, they mapped the lunar surface in different roughness parameters and they found vastly different roughness properties for the lunar highlands and the mare plains. Bandfield et al. (2015) found that Nadir observations can be modeled using $20^{\circ} \mathrm{rms}$ slope distribution, while multiple emission angle observations are best matched by a 20 $35^{\circ}$ distributions. Their data did not show any clear variation in roughness between different regions or surface units. However, Rubanenko et al. (2020) used telescope (Sinto 1962) and LRO Diviner data (Bandfield et al. 2015) to produce a detailed lunar surface roughness map. They list $30.2^{\circ} \pm 5.9^{\circ}$ (Maria) and $36.8^{\circ} \pm 4.4^{\circ}$ (Highlands) as representative values for the bidirectional rms slope at the thermal insolation scale, consistent with results presented by Bandfield et al. (2015) and Rozitis \& Green (2011). In the context of our study of disk-integrated thermal measurements of the Moon, it is important to note that the roughness properties derived from baselines up to the multiplekilometer range dominates the measured thermal-IR beaming effects of the unresolved Moon observed by the HIRS instrument (see also Rozitis \& Green 2011).

\section{TPM Moon predictions \& HIRS data}

Based on the given sun illumination and observing geometries (see Tables 1 and 2) and the above-listed size, shape, and spin properties, we made TPM flux density predictions for a direct comparison with the measurements. The slow rotation combined with low-conductivity surface layers dramatically reduce the influence of the thermal inertia on the day-time temperatures. Therefore, modifications of this value to account for temperature

${ }^{20}$ https://speclib.jpl.nasa.gov/library variations or regional differences are not needed and, thus, we keep it fixed at $55 \mathrm{~J} \mathrm{~m}^{-2} \mathrm{~K}^{-1} \mathrm{~s}^{-1 / 2}$. The crucial properties in our study are albedo, emissivity, and surface roughness.

\subsection{Influence of roughness}

The greatest influence (or uncertainty) in our TPM flux prediction comes from the surface roughness. In a first test, we set the model emissivity values to 1.0 at all HIRS wavelengths. This setting enables a direct comparison with the measured spectral emissivity properties for multiple lunar samples (Salisbury et al. 1997). We also did not account for the reflected sunlight (see spectral energy distribution (SED) part below $\approx 2.5 \mu \mathrm{m}$ in Fig. 4). Figures 2 and 3 show the measured and calibrated absolute radiances versus wavelengths and phase angle, respectively. Figure 5 shows all HIRS measurements, taken between $-60^{\circ}$ and $+60^{\circ}$ phase angles ${ }^{21}$, divided by TPM predictions, assuming a constant albedo of 0.1. ECOSTRESS spectra (calculated as 1 reflectance) of two lunar mare samples (solid lines), while two highland spectra (dotted-dashed lines) are overplotted to guide the eye. At short wavelengths below $10 \mu \mathrm{m}$, the lower roughness with a rms slope of $20^{\circ}$ (top part of Fig. 5) pushes the ratios to a good match with dark maria emissivity spectra. At very short wavelength (below $5 \mu \mathrm{m}$ ) the influence of reflected sunlight becomes apparent and the measured fluxes exceed the characteristic lunar spectra. A higher surface roughness with a rms slope of $40^{\circ}$ (bottom part of Fig. 5) increases the TPM fluxes, hence, the displayed ratios go down. The high roughness matches the long-wavelength $(\lambda>10 \mu \mathrm{m})$ very well, but does not follow any of the lab spectra in the $6-10 \mu \mathrm{m}$ range. The roughness has also an effect on the phase curves. A low roughness in the model setup underestimates the true fluxes close to full Moon and overestimates the ones at large phase angle. For high levels of surface roughness, we see the opposite. In Fig. 5 (inserted plots), we show this effect for our two extreme roughness levels (rms of $20^{\circ}$ and $40^{\circ}$ ) for channel 08 at $11.1 \mu \mathrm{m}$. The dotted lines are second-order fits to the resulting ratios. The other channels show a similar behavior. At an intermediate roughness level (best solution is at $\approx 32^{\circ}$ ), the observed phase curves are matched by the TPM predictions and the fits through the ratios are flattened out.

None of the different surface roughness levels bring the TPM predictions into agreement at all wavelengths with the available ECOSTRESS lunar emissivities for the Apollo samples. If we assume that the lunar maria spectra are more relevant (darker zones are hotter and contribute more to the thermal emission at these wavelengths) then this would point to a strongly wavelength-dependent surface roughness (low roughness values at short wavelengths and high values at longer wavelengths) that is unphysical. The emission measured by HIRS originates from the very top few millimeters to centimeters of the surface (the thermal skin depth is $\approx 1 \mathrm{~cm}$ ) and baselines up to several kilometers play a role for the relevant roughness properties (see also Rosenburg et al. 2011; Rozitis \& Green 2011; Rubanenko et al. 2020). Rozitis \& Green (2011) summarized lunar roughness studies on different scales, including results from radar measurements. They analyzed 10-12 $\mu \mathrm{m}$ scans of the sunlit portion of the Moon obtained by Saari \& Shorthill (1972) and found that rms slopes close to $32^{\circ}$ explain the lunar IR beaming effect in the most consistent way. Our best-fit roughness solution confirms this value and we use it as default from now on for all HIRS channels.

${ }^{21}$ We excluded the NOAA-17 data from 2002 taken at $\alpha=50.5^{\circ}$ where the Moon might have been partly outside the FOV at the longest wavelengths. 

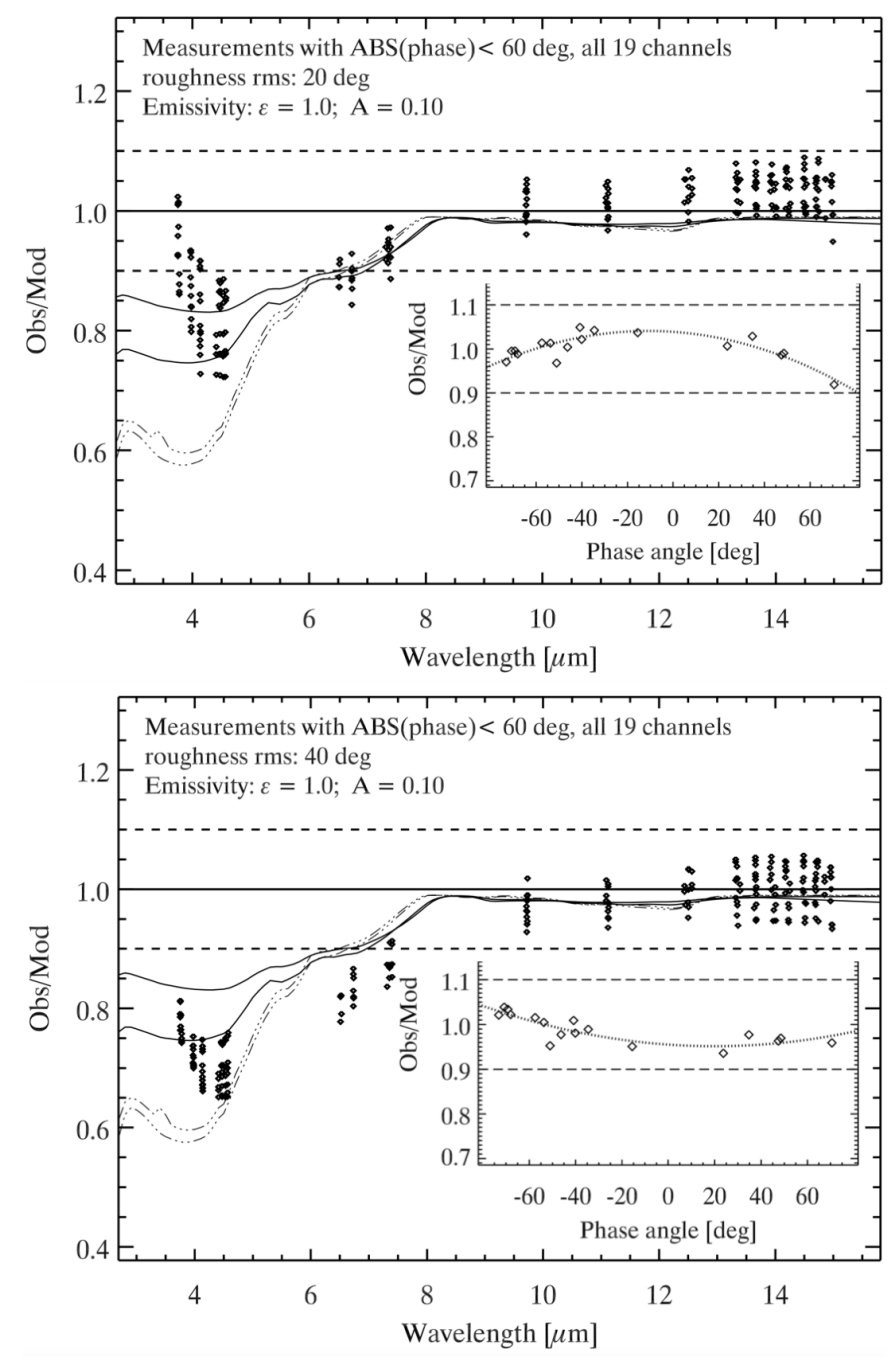

Fig. 5. Observations divided by TPM predictions $(\epsilon=1.0$; albedo $A=0.10$ ) as a function of wavelengths (and for channel 08 at $11.1 \mu \mathrm{m}$ also as a function of phase angle in the inserted figures). The measurements are shown as diamond symbols, the scatter within each channel or wavelength is associated to a small but systematic deviation dependent on phase angle. The ECOSTRESS emissivity (calculated as 1-reflectance) spectra for two extreme maria samples (solid lines) and two extreme highland samples (dotted-dashed lines) are shown. All other (maria, transition \& highland) samples would fall between these lines. Top: for a low surface roughness (rms $\left.20^{\circ}\right)$. Bottom: using a high roughness $\left(\mathrm{rms} 40^{\circ}\right)$ in the TPM. The dotted lines in the phase angle plots are second order fits through the ratios.

\subsection{Global versus local albedo}

In a second test, we set the model emissivity values again to 1.0. For the surface roughness we use the best-fit rms slope of $32^{\circ}$ and we only modify the albedo. In principle, the global average of $A=0.12$ is known, but we tested for lower and higher values. We used an albedo of 0.07 (average maria value) and 0.16 (average highland value) in the model calculations.

The effects of different albedo values are slightly smaller than the ones found for roughness and the comparison with the measurements looks very similar to the ratios shown in Fig. 5 (low albedo has a similar effect as high roughness and vice versa). The thermal IR fluxes at short wavelengths are modeled best by a low, mare-like albedo. At the long HIRS wavelengths the measurements are in better agreement with an intermediate

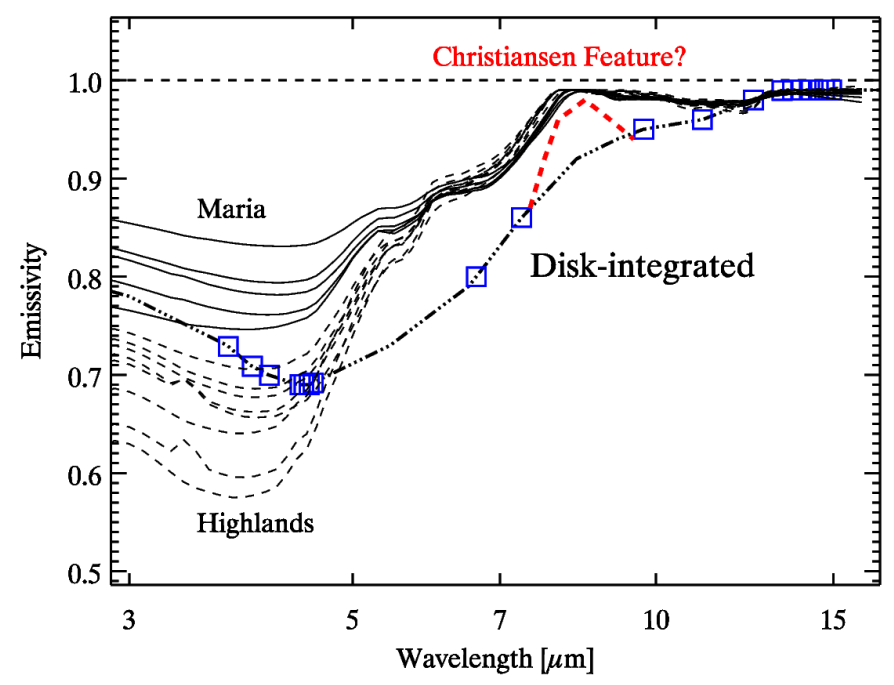

Fig. 6. Available maria (solid lines) and highland (dashed lines) ECOSTRESS lunar hemispherical emissivities together with our emissivity spectrum (dotted-dashed line) derived from global, diskintegrated Moon measurements (blue square boxes). Our model emissivity is not very well constrained at wavelength below $4 \mu \mathrm{m}$ (due to reflected sunlight contributions) and in the ranges $4.6-6.5 \mu \mathrm{m}$ and 7.3-9.7 $\mu \mathrm{m}$ (due to the lack of measurements).

albedo value around 0.1. Very high albedo values (0.16) underestimate the long-wavelength data and the observation-to-model ratios systematically exceed 1.0 .

The albedo signature in the data is clear: the darkest terrains on the surface are the hottest and the highest temperatures dominate the observed fluxes at short wavelength. At longer wavelengths, closer to the thermal emission peak, more and more lower-temperature zones contribute to the disk-integrated fluxes, closely related to a global average albedo value. Since our TPM setup uses only a single albedo for the entire Moon, we took, similarly to the work by Rozitis \& Green (2011), a value of $A=0.10$.

\subsection{Emissivity}

One of the goals was the production of a lunar TPM setup that explains the HIRS data with the best possible accuracy. Therefore, we had to establish our own spectral emissivity model from the HIRS data. Once again, we produced the observation-tomodel ratios with our default roughness $\left(\mathrm{rms}=32^{\circ}\right)$ and albedo $(A=0.10)$ values and assuming a constant flat emissivity of 1.0. This is shown in Fig. 6, together with the available lunar mare and highland spectra. There are five additional "transitional" samples that are not shown, but they look very similar and lie in the middle between these dark and bright materials. Our new global lunar emissivity model was established by a fit through all HIRS channels (dashed-dotted line in Fig. 6).

It is interesting to see that the global hemispherical emissivity as derived from our HIRS measurements roughly agrees with the averaged maria and highland spectra, both at short wavelengths below $5 \mu \mathrm{m}$ and also at long wavelengths beyond $11 \mu \mathrm{m}$. At intermediate wavelengths between 5 and $11 \mu \mathrm{m}$ (HIRS channels $12,11,09$, at $6.5,7.3$, and $9.7 \mu \mathrm{m}$, respectively), the measured effective global emissivity differs clearly from the lunar sample emissivities (Salisbury et al. 1997). There are no indications from the HIRS calibration activities that these three channels have any calibration issues. Another important aspect 


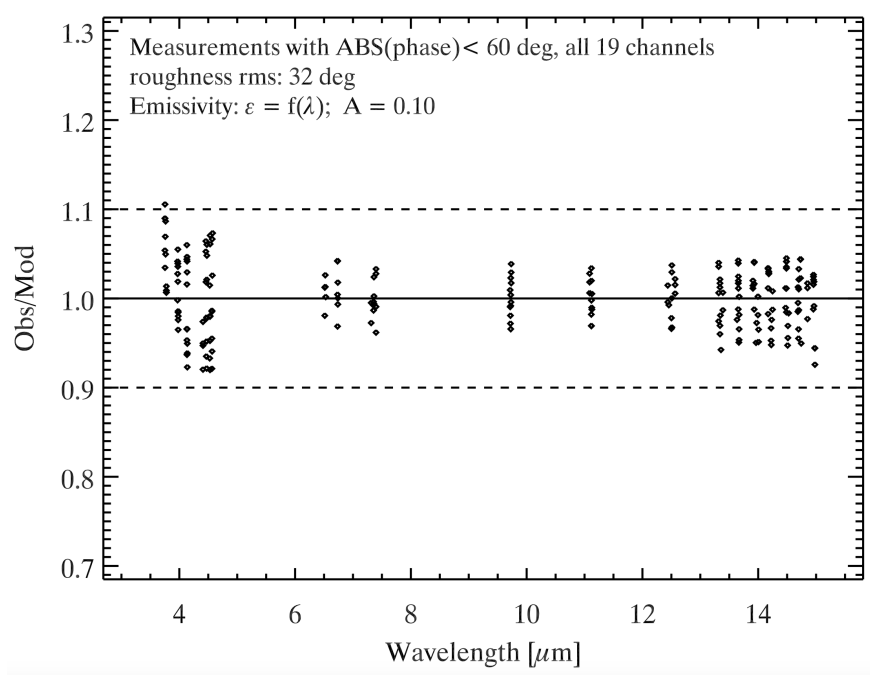

Fig. 7. Observations divided by TPM predictions, using the default rms slopes of $32^{\circ}$ and an albedo A of 0.1 , but now with a hemispherical spectral emissivity derived from the corresponding observation-to-model ratios. The reflected light contribution is again visible as an increase of the ratios at the shortest wavelengths.

is that at wavelengths between the HIRS channels, we have no information on the hemispherical emissivity. The regions between 4.6 and $6.5 \mu \mathrm{m}$ and between 7.5 and $9.5 \mu \mathrm{m}$ stand as the most prominent gaps. Here, the true values are not constrained by our measurements. In particular, one problematic region for our model is located in the range of the Christiansen feature (e.g., Murcray et al. 1970; Greenhagen et al. 2010). This feature is located between $\approx 7.5$ and $9.0 \mu \mathrm{m}$ (indicated by the red dashed line in Fig. 6). Vasavada et al. (2012) found peak emissivities of 0.96 to 0.98 in the 8 to $8.5 \mu \mathrm{m}$ range, related to specific locations on the lunar surface. This work was based on the three mineralogy channels (A3: $7.80 \pm 0.25 \mu \mathrm{m}$; A4: $8.20 \pm 0.22 \mu \mathrm{m}$; A5: $8.60 \pm 0.20 \mu \mathrm{m}$ ) of the Diviner Lunar Radiometer Experiment. The HIRS channels have no overlap with the Diviner channels and have very narrow filters (see Fig. 2). Therefore, they cannot be used to constrain the global emissivity in the range of the Christiansen feature. Another aspect which limits our comparison is that the lunar samples have been measured under particular temperatures and illumination or observing angles, while the HIRS-derived emissivities are the result of combined multi-angle and multi-temperature conditions on the surface of the Moon. But the dominating reason for the discrepancy is not clear. Further full-disk measurements are needed to confirm our findings and to fill the gaps between the HIRS channels in order to achieve a characterization of the global emissivity.

Using our new "lunar global emissivity spectrum", the ratios are brought close to 1.0 (see Fig. 7) while the scatter is reduced at a given wavelength or phase angle to a minimum. Beyond $5 \mu \mathrm{m}$, the TPM predictions agree now within $5 \%$ of the measured values, while at shorter wavelength, we are still within $10 \%$. Outliers are found in ch18/ch19 at very short wavelengths, where the reflected sunlight contributes a few percent to the measured values, and at the longest wavelengths, where the noise levels are higher and where it was not always perfectly clear whether the Moon was completely in the FOV.

Temperature gradients can be extremely steep in the upper few millimeters of the lunar surface (e.g., Keihm 1984; Bandfield et al. 2015), and, in the beginning, it was not clear if the different spectral channel would be sensitive to different sub-surface layers. The emission measured by HIRS originates from the very top few millimeters to centimeters of the surface. At these short wavelengths, the thermal emission is dominated by the hottest temperatures on the surface and the sub-surface would not contribute significantly to the total disk-integrated flux. This can also be seen in Fig. 7.

By applying our global spectral emissivity solution, which shows a similar behavior as the Apollo sample emissivities measured at a constant temperature, we can fit the HIRS measurements over all channels equally well. There are no indications that the different spectral channels have a depth sensitivity. In addition, asteroid thermal emission studies show that sub-surface layers seem to influence the disk-integrated fluxes only starting in the far-IR, sub-millimeter or millimeter range (see e.g., Müller et al. 2014a).

\subsection{Phase curves}

Our HIRS data cover a phase angle range from $-73.1^{\circ}$ (waxing Moon) to $+73.8^{\circ}$ (waning Moon). We consider whether the Moon phase curves at thermal wavelengths are symmetric with respect to opposition (phase angle $\alpha=0^{\circ}$ ) and whether the phase slopes are well explained by our TPM solutions. Maghrabi (2014) obtained groundbased 8-14 $\mu \mathrm{m}$ measurements over a full Moon cycle. They found that the IR temperature reaches its maximum of $391 \pm 2 \mathrm{~K}$ for the full Moon and claim a symmetric phase behavior. They also determined a temperature of $240 \pm 3.5 \mathrm{~K}$ for the first quarter, and $236 \pm 3 \mathrm{~K}$ for the last quarter.

We also looked at the HIRS brightness temperatures as a function of phase angle, but for each of the HIRS channels separately. Figure 8 shows (from top to bottom) the data from HIRS long-wavelength channels $(12-15 \mu \mathrm{m})$, mid-wavelength channels $(6-12 \mu \mathrm{m})$, and the short-wavelength channels $(4-5 \mu \mathrm{m})$. Channels 18 and 19 are affected by reflected sunlight and have been excluded. We fit each channel separately with a fifth-order polynomial, as done for the microwave range $(89-190 \mathrm{GHz})$ by Burgdorf et al. (2019). These phase curves show slightly asymmetric shapes. In the short-wavelength 4-5 $\mu \mathrm{m}$ range the fitted peak brightness temperatures $(368.0 \pm 0.9 \mathrm{~K})$ are found close to opposition at $0.2^{\circ} \pm 1.2^{\circ}$. In the LW channels, the peak brightness temperatures $(363.2 \pm 1.4 \mathrm{~K})$ are consistently shifted by $2-3^{\circ}$ towards negative phase angles $\left(-2.6^{\circ} \pm 0.7^{\circ}\right)$, that is, a few hours before full Moon. In the LW data there is even a trend for the brightness peak to move to more negative phase angles at longer wavelengths.

At much longer wavelengths in the microwave regime, Keihm (1984), Burgdorf et al. (2019) or Liu \& Jin (2020) found a significant phase shift of the diurnal maximum. The peak brightness temperature maximum occurs at a phase angle of about $20^{\circ}$ and $24^{\circ}$ at 157 and $89 \mathrm{GHz}$, respectively. The lag angle depends on the ratio between the physical thickness of the emission layer and the penetration depth (Krotikov \& Troitskii 1964). However, at the HIRS wavelengths, we only see the millimeterto-centimeter top-layer of the surface and the shift to negative phase angles is very likely related to small hemispherical differences in thermal properties (roughness and albedo), which sum up to a slightly shifted and asymmetric phase curve.

The phase curves are also relevant in the context of TPM concepts to see how well the flux predictions match the observed disk-integrated flux densities of the Moon. We take the best TPM solutions for the short- and long-wavelength HIRS regime, calculate again the ratios between observed and modeled flux densities, and show the result as a function of phase angle (see inserted plots in Fig. 8). The model includes now our disk-integrated 

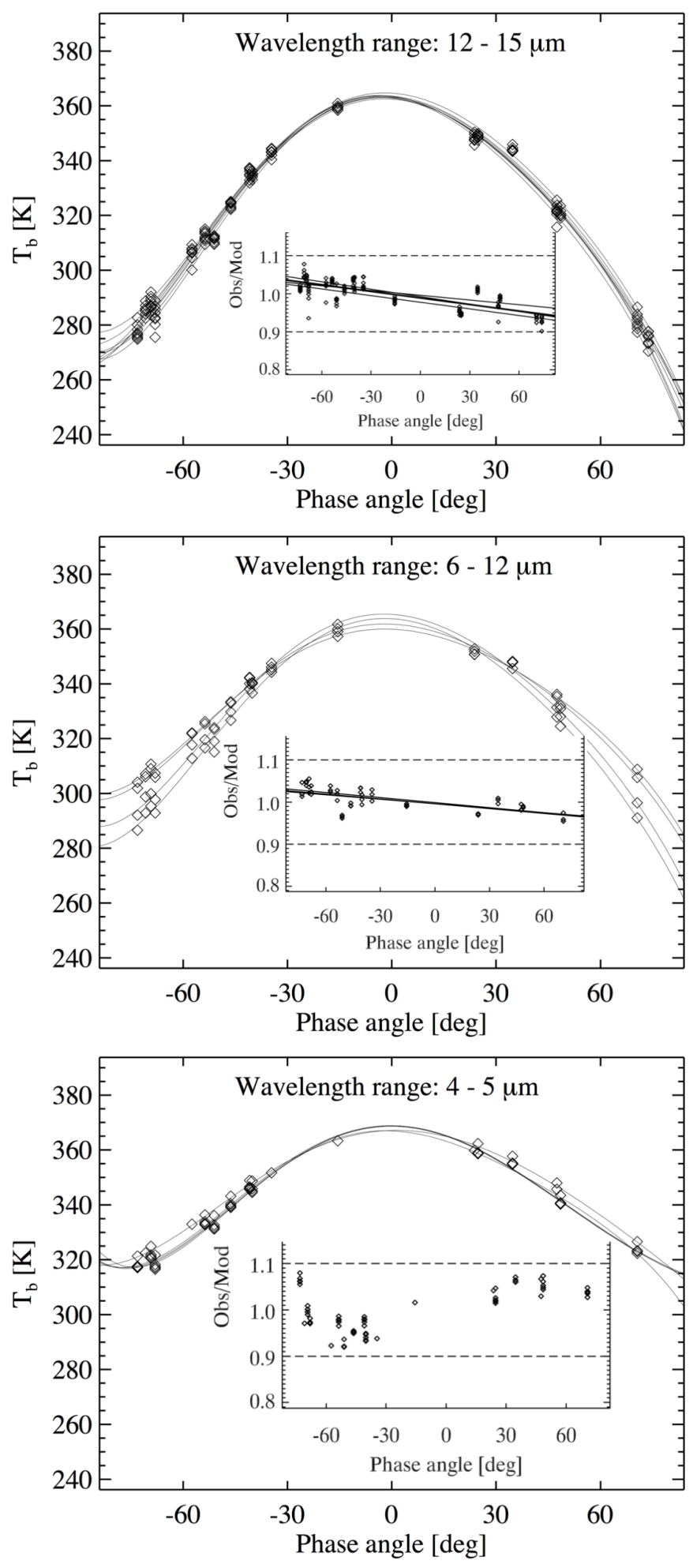

Fig. 8. Measured and calibrated HIRS brightness temperatures as a function of phase angle and fitted (in each channel separately) by a fifth-order polynomial. Top: for long-wavelength channels $(12-15 \mu \mathrm{m})$; Middle: for mid-wavelength channels $(6-12 \mu \mathrm{m})$; Bottom: for shortwavelength channels $(4-5 \mu \mathrm{m})$. Phase curves are asymmetric and with a $2-3^{\circ}$ shifted peak (towards negative phase angles) at mid to long wavelengths. The inserted plots show the corresponding flux densities divided by TPM predictions, also as a function of phase angle. The lines have been fitted in each channel separately. The before-after opposition asymmetry is clearly visible for the long- and mid-wavelengths channels. At short wavelengths, there is a wavy structure and no linear fit was done. hemispherical emissivity model and is calculated for an albedo of 0.10 , roughness rms slopes of $32^{\circ}$, and the above-listed in-situ properties. The asymmetry in the observation-to-model ratios can be corrected via the average fitted slope. In the $12-15 \mu \mathrm{m}$ range the TPM predictions have to be increased by $0.56 \pm 0.07 \%$ per $10^{\circ}$ phase angle for the waxing Moon and decreased for the waning Moon. In the 5-12 $\mu \mathrm{m}$ range the correction is smaller with only $0.35 \pm 0.06 \%$ per $10^{\circ}$ phase angle. At short wavelengths below $5 \mu \mathrm{m}$, the corrections are not as well defined (see inserted plot in Fig. 8, bottom). The wave-like sinusoidal pattern could give a first hint for possible corrections, but more data would be needed to quantify these corrections in a meaningful way.

The before-after opposition asymmetries in the residuals between observations and TPM predictions are very likely caused by temperature differences between morning and afternoon. At positive phase angles, the HIRS measurements sample mainly "morning" illuminated slopes, whereas the negative phase angles sample more afternoon-evening slopes, which are slightly hotter than the morning ones. Additional contributions might also be related to albedo (Vasavada et al. 2012) or roughness properties (Rubanenko et al. 2020) that show regional variations over the lunar surface. At large negative phase angles the illuminated fraction of the surface has probably a lower mean albedo, leading to higher temperatures and a few percent higher (than predicted) fluxes and vice versa. At the shortest wavelengths (inserted plot in Fig. 8, bottom), the trend is probably caused by small dark (or not so dark) areas that dominate the full-disk lunar emission at specific phase angles. Global mean values of albedo and roughness are less relevant.

After fitting the phase asymmetry (inserted plots in Fig. 8) in the LW channels, we find remaining deviations from the fitted lines of only 1-3\% in a given channel. The best agreement between the HIRS data and our final TPM predictions are found for channels $8-12(6.5-12.5 \mu \mathrm{m})$. In the SW channels, where fitting of the phase asymmetry was not done, the individual measurements can deviate up to $8 \%$ from our TPM predictions.

\section{Applications and discussion}

We find an excellent agreement between the HIRS measurements of the Moon and our TPM predictions when using the following model parameters: (i) the physical size, shape, rotational properties of the Moon; (ii) a thermal inertia $\Gamma=55 \mathrm{~J} \mathrm{~m}^{-2} \mathrm{~K}^{-1} \mathrm{~s}^{-1 / 2}$ (Hayne et al. 2017); (iii) a surface roughness characterized by an rms slope of $32^{\circ}$ (as in Rozitis \& Green 2011); (iv) an albedo $A=$ 0.10 ; (v) reflected light properties following the Lumme-Bowell convention: $H=-0.089 \mathrm{mag}$ (with $0.43 \mathrm{mag}$ opposition surge), $G=0.233, q=0.43$ (not crucial for thermal emission calculations); (vi) our lunar global hemispherical spectral emissivity model (see Fig. 6); and, (vii) phase-angle asymmetry model corrections of up to $+3 \%$ at $\alpha<-60^{\circ}$ and $-3 \%$ at $\alpha>+60^{\circ}$, but only for wavelengths $>6 \mu \mathrm{m}$ (see inserted plots in Fig. 8, top \& middle; corrections given in the text).

This model is valid in the wavelength ranges $5-7.5 \mu \mathrm{m}$ and 9.5-15 $\mu \mathrm{m}$ and for phase angles $-75^{\circ}<\alpha<+75^{\circ}$. For wavelengths below $5 \mu \mathrm{m}$, the TPM predictions could be off by up to $8 \%$ at specific phase angles (see inserted plots in Fig. 8, bottom). We also tested trends in the observation-to-model ratios with the heliocentric distance of the Moon (ranging from 0.985 to $1.018 \mathrm{au}$ ), the Moon's angular diameter or satelliteMoon distance (ranging from 1756.5 to 1975.7", and from 362777.3 to $408034.0 \mathrm{~km}$, respectively), the sub-observer's 


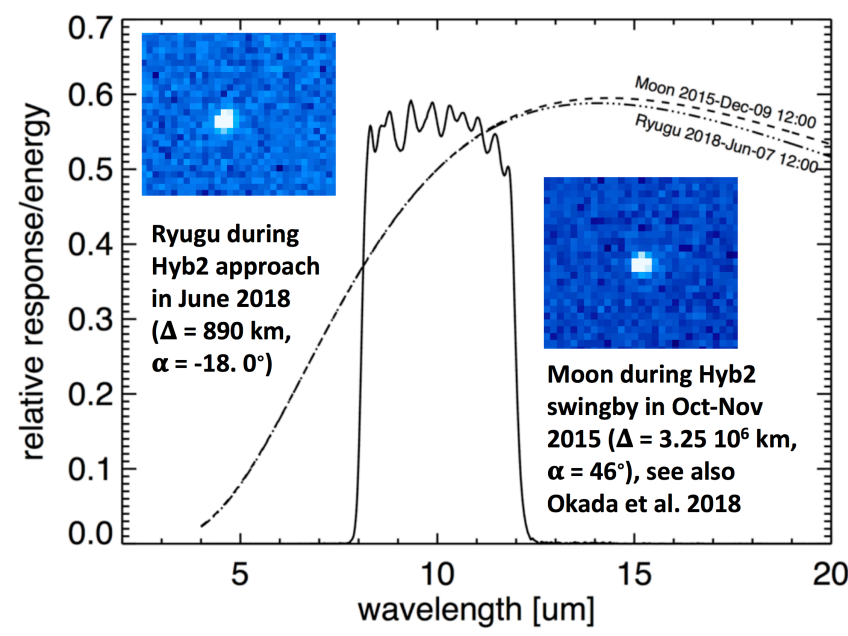

Fig. 9. TIR passband (in relative detector response per energy) in solid line. In addition, the SED shapes of the Moon (during the Hayabusa-2 flyby in 2015; dashed line) and Ryugu (during close-proximity operations in 2018; dashed-dotted line) are shown (arbitrary flux scale). Both SED shapes are very similar in the TIR passband. This allows for a direct calibration of the TIR Ryugu measurements via (global) lunar model predictions, without any color-correction terms.

longitude $\left(351.2-6.8^{\circ}\right)$ and latitude $\left(-5.6\right.$ to $\left.+6.8^{\circ}\right)$, the sub-Solar latitude $\left(-1.6\right.$ to $\left.+1.5^{\circ}\right)$, and the calculated aspect angle (83.5 to $\left.95.6^{\circ}\right)$, but no obvious correlation has been found.

It is worth noting that our 3\% accuracy in model predictions can be translated into an approximate error in brightness temperature. At $5 \mu \mathrm{m}$, a flux density change of $3 \%$ would translate into a brightness temperature change of $0.8 \mathrm{~K}$ for an assumed body temperature of $280 \mathrm{~K}$. At $10 \mu \mathrm{m}$, the $3 \%$ flux change translates into $1.6 \mathrm{~K}$, and at $15 \mu \mathrm{m}$, the $3 \%$ correspond to $2.4 \mathrm{~K}$, always referring to a $280 \mathrm{~K}$ object.

\subsection{Interplanetary missions: thermal IR measurements of the Moon}

The new thermal model for the global, disk-integrated thermal emission of the Moon can now be used for calibrating infrared instruments of interplanetary missions. The Hayabusa2 mission (Tsuda et al. 2016) visited the near-Earth C-type asteroid 162173 Ryugu and performed a detailed characterization of the mission target (e.g., Kitazato et al. 2019; Watanabe et al. 2019; Sugita et al. 2019). It revealed the highly porous nature of this primitive asteroid (Okada et al. 2020) from thermo-graphic images taken by the thermal infrared imager (TIR; Okada et al. 2017). This instrument was calibrated on ground and used for the first scientific measurements during an Earth-Moon flyby in December 2015 (Okada et al. 2018). Figure 9 shows the (calculated and arbitrarily scaled) thermal spectra of the Moon (dashed line) and Ryugu (dashed-dotted line), together with the thermal images of both targets as small inlays. Both spectral energy distributions are extremely similar in the $5-15 \mu \mathrm{m}$ range despite the very different physical and thermal properties of these bodies. The TIR passband (shown as solid line) covers the 8-12 $\mu \mathrm{m}$ range. The uncertainties in our global emissivity solution in the range of the Christiansen feature are very likely not critical as it is located at the edge of the TIR filter transmission profile. With the help of our new global lunar model, the TIR measurements of the Moon (taken at phase angles in the ranges -59 to $-55^{\circ}$ and +45 to $+60^{\circ}$ ) are currently used to consolidate the
TIR in-flight detector response and to establish firm correlations between measured signals and absolute flux densities. The TIR Moon measurements were taken at different distance from the Moon, covering about three orders of magnitude in count rates. Our TPM predictions are taken to characterize the linearity of the detector response over this wide range, and to understand the size-of-source effect (e.g., Hill \& Woods 2005; Saunders 2013) which is critical for counts-to-temperature conversion in the TIR calibration process (see supplementary material in Okada et al. 2020). More TIR measurements of the Moon have been taken during the return of the Hayabusa-2 sample container in December 2020, and more are planned in December 2027 and June 2028 during Earth swing-by maneuvers on its mission extension to asteroids $2001 \mathrm{CC}_{21}$ and $1998 \mathrm{KY}_{26}$.

BepiColombo, an interplanetary mission to Mercury, carries the Mercury Radiometer and Thermal Infrared Spectrometer (MERTIS). During an Earth flyby in April 2020 MERTIS collected hyper-spectral 7-14 $\mu \mathrm{m}$ observations of the Moon (D'Amore et al. 2020). The goal of these measurements was to test different instrument (acquisition, binning, calibration) modes and to deliver the first calibrated data acquired in space for the BepiColombo community. Here, our lessons learnt from the HIRS data and our TPM Moon predictions could be very useful to reach these goals.

The OSIRIS-REx mission to asteroid Bennu (Lauretta et al. 2017) also obtained thermal spectra of the Moon (at $\alpha=42^{\circ}$ ) with the OSIRIS-REx Visible and InfraRed Spectrometer (OVIRS, 0.4-4.3 $\mu \mathrm{m}$; Simon et al. 2019) and the Thermal Emission Spectrometer (OTES, 5.7-100 $\mu \mathrm{m}$; Christensen et al. 2018) during an Earth flyby in September 2017. The OVIRS full-disk spectra included the 2.8- $\mu \mathrm{m}$ hydration band and showed evidence of several other absorption features. The thermal emission in the range $>2.8 \mu \mathrm{m}$ had to be subtracted for the spectral interpretation of the measurements. They modeled the thermal emission as a single blackbody temperature of $382.5 \mathrm{~K}$ with a wavelengthindependent emissivity of $\epsilon=0.167$. For both, the OVIRS spectra and also the unpublished OTES data, our full-disk TPM predictions at specific phase angles and wavelengths would be useful for calibration purposes and the scientific exploitation of the measurements. In addition, the MERTIS and the OSIRISREx/OTES spectra will be important to identify any discrepancies between our global emissivity solution at regions not covered by the HIRS channels.

\subsection{Earth-observing and weather satellites: IR scans of the Moon}

The Moon is also widely used to calibrate space-based Earth observing instruments (e.g., Barnes et al. 2004; Matthews 2008; Burgdorf et al. 2019) as a radiative target to characterize beam properties, to monitor calibration stability, or to inter-compare detector responses of different instruments or projects. The Clouds and the Earth's Radiant Energy System (CERES) measures the Earth radiation budget from two polar orbiting satellites. In addition to high-accuracy broadband measurements of the scattered and thermal emission, they also perform narrowband (called WN) $8-12 \mu \mathrm{m}$ thermal radiance studies. Thanks to regularly obtained Moon scans (Matthews 2008), it was possible to reduce instrument calibration drifts to $0.3 \%$ per decade and to perform inter-instrument comparisons, in addition to studying the instrument's optical degradation. However, according to Matthews (2008), the usage of lunar WN data was suffering from the lack of knowledge about the lunar disk emissivity and temperature distribution. Here, our disk-integrated 
hemispherical emissivity model as well as the calculated temperature distribution will be very useful to convert the WN-channel measurements into a broad-band thermal flux and to improve the absolute accuracy of WN calibration concepts. On the other hand, the CERES WN data, typically taken in the phase angle range $11^{\circ}$ to $3^{\circ}$ before and after opposition, will nicely complement our lunar TPM testing. Unfortunately, these data were not available for our studies.

The Moon measurements have also been used for the calibration of weather satellites. Burgdorf et al. (2020) settled a long-standing question about the field of view of the channels in the HIRS instrument versions 2, 3, and 4. With the contribution of specific Moon intrusions, they were able to determine the precise pointing direction for each channel and they found differences of up to $0.031^{\circ}$ and up to $0.015^{\circ}$ for the long- and shortwavelength channels, respectively. The photometric agreement is consistent within about $1 \%$ for most channels and instruments. They also provided upper limits for the non-linearity effects in the short-wavelength channels.

Other infrared sounders, such as CERES (Daniels et al. 2014) or IASI ${ }^{22}$, have extensively observed the Moon, and future instrument generations, such as the IASI-New Generation or the Meteorological Imager on Metop Second Generation, will also see the Moon. This makes our model an ideal tool for cross-calibration exercises. It can also provide the grounds for monitoring instrument or detector aging and degradation effects.

Based on the available HIRS Moon detections, we intercompared the calculated ratios for a given channel (or a small subset of channels) per instrument (HIRS/2, HIRS/3, and HIRS/4). We noticed that the HIRS/3 ratios are on average about $5 \%$ lower than the HIRS/ 2 or HIRS/4 ratios. But the statistics for HIRS/ 3 are poor and some of the HIRS/ 3 data are flagged with the Moon potentially touching the edge the FOV. In addition, all the HIRS $/ 2$ data were taken at negative phase angles $\left(-71^{\circ}\right.$ to $-34^{\circ}$ ), while all the HIRS/3 measurements are in the positive phase angle range $\left(+23^{\circ}\right.$ to $\left.+73^{\circ}\right)$. Only the HIRS/4 data cover the full range of angles. However, with the availability of more Moon intrusions, this would be the right path to intercompare the absolute calibration of the instruments, find detector aging effects, or test possible small deviations in the beam size.

\subsection{Thermal modeling of asteroids}

With the availability of large sets of thermal asteroid observations taken at short wavelengths, there is a need to attain a better understanding of the applied radiometric techniques. The HIRS data (Tables A.4 and A.5) are excellent for testing and verifying thermal models and for characterizing possible error of the derived parameters. The analysis of the HIRS Moon data reveal the critical concepts and shortcomings for the application to asteroid observations at short thermal wavelengths:

First, in cases where asteroids show regions with different albedos, the standard radiometric size-albedo solutions (using only short-wavelength thermal data) will be biased towards the lowest albedo values. Hence, albedo variations can bias the size determination to larger sizes ${ }^{23}$.

Second, surface roughness - at scales that are larger than the thermal skin depth and smaller than the resolution of the global

\footnotetext{
${ }^{22}$ Infrared Atmospheric Sounding Interferometer; https://wwW . mdpi . com/2072-4292/12/9/1488

${ }_{23}$ A low-albedo small object can have the same thermal flux as a higheralbedo and larger body.
}

shape model - is crucial for the interpretation of observations taken well below the thermal emission peak and at large phase angles (mainly relevant for near-Earth objects; see also Fig. 5). Uncertainty in the emissivity properties leads to unrealistic roughness values (see the case of Ryugu below).

Third, unknown hemispherical emissivity properties introduce substantial errors in the radiometric determination of size-albedo solutions when using only short-wavelength observations. In addition, in cases where thermal data cover a wide range in wavelengths that also includes mid-IR data, radiometric studies can lead to erroneous object properties when a constant spectral emissivity is assumed.

Next, laboratory spectral emissivity studies of typical surface materials might not have a one-to-one correspondence to fulldisk spectra. There are also strong vacuum effects on emissivity spectra.

And last, for near-Earth objects, reflected sunlight contributions must be accounted for before interpreting thermal measurements below $\approx 5 \mu \mathrm{m}$.

\subsubsection{NEATM applications}

The near-Earth asteroid thermal model (NEATM; Harris 1998) is widely used for radiometric studies of asteroids (see Harris \& Lagerros 2002, for a review). It assumes a non-rotating spherical object with a non-conducting, perfectly smooth surface with constant emissivity and albedo. To compensate for these simplifying assumptions, a single parameter $\eta$, called the beaming parameter, can either be fitted to the thermal emission spectrum or used with a default value when multi-wavelength data are not available. A value of 1.0 has been widely used for mainbelt asteroids observed at phase angles well below $45^{\circ}$ and 1.5 for larger phase angles typical of near-Earth asteroids, but other values have been applied in the past (e.g., Delbo' et al. 2007; Wolters \& Green 2009; Müller et al. 2011, 2020; Mainzer et al. 2016; Alí-Lagoa et al. 2018; Mommert et al. 2018).

In recent years, IR sky surveys such as WISE or dedicated projects with Spitzer-IRAC produced a wealth of data in the 3.5$5 \mu \mathrm{m}$ range. The NEATM applications at short thermal wavelengths and in the presence of reflected sunlight are addressed in different works related to NEOWISE data or Spitzer-IRAC observations (e.g., Mainzer et al. 2015, and references therein), but the correct application techniques and potential errors are under discussion (Mommert et al. 2018; Myhrvold 2018; Wright et al. 2018; Masiero et al. 2021). Here, the HIRS channels 13-19 provide a very useful means of investigating emissivity properties that are different from the standard $\epsilon$-solutions with constant values of 0.9 or 0.95 .

For the HIRS data of the Moon, we find $\eta$-values of 0.9 for the smallest phase angle of $15.6^{\circ}$ up to values of 1.2 at the largest phase angles $>70^{\circ}$. It is important to note that for a given multi-wavelength observation, the fitted $\eta$ can vary significantly, depending on the given subset of channels used in the analysis. At short wavelengths (without ch18 and ch19, where reflected sunlight is contributing), we see $\approx 5-10 \%$ higher $\eta$ values, up to about 1.25 at short wavelengths and large phase angles. In the long-wavelength channels we find systematically lower $\eta$-values, down to about 0.8 at $\lambda>12 \mu \mathrm{m}$ and small phase angles. Also, we found that fitting $\eta$ to data below $5 \mu \mathrm{m}$ is very uncertain and leads to huge errors in size-albedo solutions. If we take the fullwavelength-fitted best $\eta$-values (between 0.9 and 1.2, depending on the phase angle: see above) and apply the NEATM to the HIRS data, we can reproduce the Moon's size to within 5-10\% (and the albedo to within 10-20\%) at all wavelengths beyond 
about $4 \mu \mathrm{m}$, which is consistent with the error bars expected for the model when applied to asteroids (see e.g., the discussion in Alí-Lagoa et al. 2018). This error range is only applicable in cases where the available thermal data allow for a high-quality $\eta$ fit and where the thermal parameter (Spencer et al. 1989) is small. For much faster rotating objects, high thermal inertia surfaces, or complex shapes, the NEATM size-albedo solutions are naturally more uncertain.

\subsubsection{TPM applications}

The TPM techniques discussed above are typically applied to asteroids with known spin (and possibly also shape) information. The goal is to determine the object's true size and albedo and to constrain its thermal inertia and surface roughness. In some cases, the TPM analysis also helps to improve the quality of the spin and shape solutions (e.g., Müller et al. 2017, 2019). But the success of these methods strongly depends on the availability and quality of thermal measurements. Based on our HIRS data, we can perform a radiometric study of the Moon by simply using its known spin and shape. But we also consider how well such a procedure reproduce the Moon's size without having any information about its hemispherical spectral emissivity. We consider what types of constraints on thermal inertia and surface roughness we may obtain by using a typical approach used for asteroids.

Running a standard TPM radiometric analysis on the HIRS data produces results with severe implications for asteroid studies. We leave size, albedo, thermal inertia, and surface roughness as free parameters. We take a spherical shape with the Moon's true spin properties (spin-axis orientation and synodic rotation period) and assume a constant spectral emissivity of $\epsilon=0.9$ (or $0.95)$, as is frequently used in asteroid studies.

The first finding, which was already expected from the Moon's very slow rotation, is that the thermal inertia cannot be determined from our data. Low $\Gamma$-values of 10 SI-units produce the same size-albedo solution as $\Gamma$-values well above 100 SI-units. However, the HIRS data include a strong signature of surface roughness. At short wavelengths (and to a lesser extent, also at long wavelengths), an intermediate level of surface roughness is needed (close to $\mathrm{rms}$ of $30^{\circ}$ ) to produce consistent size-albedo solutions (with acceptable $\chi^{2}$ values) over all phase angles. With such an intermediate level of surface roughness, the LW data ( $\lambda$-range from 6.5 to $15 \mu \mathrm{m}$ ) directly produce a radiometric size which is within $10 \mathrm{~km}$ of the Moon's true diameter ( 3488 vs. $3474.8 \mathrm{~km}$ ). However, at short-wavelength data, the constant- $\epsilon$ assumption leads to a size which is about $15 \%$ lower, that is, well below $3000 \mathrm{~km}$, even after cleaning the SW data from the channels below $4 \mu \mathrm{m}$ and the extreme phase angles $\left(<-70^{\circ}\right.$ and $\left.>+70^{\circ}\right)$. At short wavelengths, we need lower roughness (down to a smooth surface) to match the radiometric size to the Moon's true size. But this violates the constraints from the phase curve. A smooth surface is incompatible with the measured flux change with phase angle. The solution to the problem is clearly related to the Moon's lower spectral emissivity at short wavelengths. This is an important aspect when trying to apply radiometric techniques to short-wavelength, often single-epoch, asteroid data. Müller et al. (2017) analyses a collection of pre-mission thermal measurements of 162173 Ryugu, the Hayabusa- 2 target asteroid. The data set was dominated by short-wavelength Spitzer-IRAC data at 3.55 and $4.49 \mu \mathrm{m}$. And as a result, the best-fit radiometric solution pointed towards a smooth surface. This setting was required to bring the short- and long-wavelength data into agreement and to obtain an acceptable $\chi^{2}$ size-albedo solution ${ }^{24}$. Recently, the Hayabusa- 2 data revealed a surface roughness $\mathrm{rms}$ of $47^{\circ} \pm 5^{\circ}$ (Shimaki et al. 2020). This high level of surface roughness (compared to the $32^{\circ}$ for the Moon) is in contradiction to the smooth surface predicted by Müller et al. (2017) and points toward shortcomings in their radiometric study. We repeated the analysis of the pre-mission IR measurements of Ryugu (the 24 best-quality measurements from Müller et al. 2017), but now using the in-situ size, shape, spin (Watanabe et al. 2019), and surface roughness properties $\left(47^{\circ} \pm 5^{\circ}\right.$; Shimaki et al. 2020).

In a first approach, we used standard constant spectral emissivity of 0.9 , then, in a second step, we applied the HIRS-based lunar spectral emissivity, always with the goal of constraining the object's thermal inertia via $\chi^{2}$ minimization techniques (e.g., Alí-Lagoa et al. 2020). On the one hand, the default $\epsilon=0.9$ assumption leads to a thermal inertia above $1000 \mathrm{~J} \mathrm{~m}^{-2} \mathrm{~s}^{-0.5} \mathrm{~K}^{-1}$ (for acceptable reduced $\chi^{2}$ values below 2 ). On the other hand, with the lunar global emissivity model we found an acceptable minimum $\chi^{2}$ close to 1.0 . The corresponding thermal inertia is between 150 and $400 \mathrm{~J} \mathrm{~m}^{-2} \mathrm{~s}^{-0.5} \mathrm{~K}^{-1}$, very close to the published values of about $300 \mathrm{~J} \mathrm{~m}^{-2} \mathrm{~s}^{-0.5} \mathrm{~K}^{-1}$ (Okada et al. 2020) and $225 \pm 45 \mathrm{~J} \mathrm{~m}^{-2} \mathrm{~s}^{-0.5} \mathrm{~K}^{-1}$ (Shimaki et al. 2020). This example illustrates the importance of realistic spectral emissivity in the context of radiometric studies based on short-wavelength $(<10 \mu \mathrm{m})$ thermal measurements.

\section{Conclusions}

With our collection of NOAA- and MetOp-HIRS Moon detections, we are able to provide a unique thermal dataset for characterizing the global thermal properties of the Moon and for testing and benchmarking asteroid thermal models. The HIRS full-disk lunar fluxes cover a wavelength range from 3.75 to $15.0 \mu \mathrm{m}$ and a phase angle range from $-73.1^{\circ}$ (waxing Moon) to $+73.8^{\circ}$ (waning Moon), taken between 1989 and 2019. The measurements are absolutely calibrated with an estimated uncertainty of $3 \%$ or less, except in the few cases where the Moon was possibly touching the edge of a given channel FOV. Since these measurements are dominated by thermal emission of the sunlit regions, they have no or very little information about the Moon's global thermal inertia. However, they contain a strong signature of the global surface roughness properties. This is seen in characteristic flux changes with phase angle which point to a roughness rms of surface slopes close to $32^{\circ}$, confirming the findings of Rozitis \& Green (2011, and references therein).

The correct roughness description allows us to combine the HIRS data taken over this very wide phase angle range from almost first quarter (waxing) to third quarter (waning). In a second step, it was then possible to examine the Moon's hemispherical spectral emissivity. Emissivity values determined from the HIRS data lead to a partial match to the mean characteristics of lunar mare and highlands at very short and very long HIRS wavelengths. The global emissivity solution shows values as low as 0.69 at $4.5 \mu \mathrm{m}$ and then slowly increasing to values close to 1.0 at $12 \mu \mathrm{m}$. In the intermediate wavelength range, at $6.5 \mu \mathrm{m}$ (channel 12), $7.3 \mu \mathrm{m}$ (channel 11), and $9.7 \mu \mathrm{m}$ (channel 09), the HIRS-based emissivity is about 5-10\% lower than the values derived from the Apollo samples of lunar mare, highlands

\footnotetext{
${ }^{24}$ Müller et al. (2017) derived an effective diameter of 850-880 m, a geometric albedo of $0.044-0.050$, and a thermal inertia $\Gamma$ in the range $150-300 \mathrm{~J} \mathrm{~m}^{-2} \mathrm{~s}^{-0.5} \mathrm{~K}^{-1}$ which is in excellent agreement with Ryugu's true properties from in-situ studies.
} 
and transition regions. In the region of the Christiansen feature (between channel 11 and channel 09) significantly higher emissivity values are expected, but this range is not covered by the HIRS channels.

The combined HIRS data helped us to establish a global lunar TPM. This model solution allows us to predict the Moon's full-disk emission for a wide range of phase angles and wavelengths, with the exception of the region covered by the Christiansen feature. Our model predictions reach an absolute accuracy of better than about $5 \%$ in the mid-IR regime (and better than about $10 \%$ at the shortest wavelengths below $5 \mu \mathrm{m})$. We still see an asymmetric emission before and after opposition and our model starts to deviate a few percent from observations at the extreme phase angles $\left(|\alpha|>75^{\circ}\right)$ based on the given wavelength range and whether the phase is waxing or waning (see Sect. 4.4). However, for highly accurate model applications, it is possible to correct these small offsets by manual corrections based on our linear fits.

The applications of the HIRS data are manifold. Thermal-IR instrumentation on weather satellites and interplanetary missions are using the Moon as in-flight calibrator to improve the knowledge on beam characteristics or to verify detector response and linearity properties. What is of particular interest is the potential for inter-calibration and checking the photometric stability of instrumentation on weather satellites. The Moon appeared in the DSV of HIRS/2 as early as 1983. The radiances measured back then can be compared immediately with those obtained in 2020 by HIRS/4 on Metop satellites, when a model can provide the exact dependence of the radiance from the phase angle of the Moon and its distance to the Sun. Such a model offers therefore the intriguing possibility of reliable time series of essential climate variables over almost four decades. With respect to HIRS, here we think, in particular, of the upper tropospheric humidity, whose response to $\mathrm{CO}_{2}$ forcing plays an important role in climate models.

However, our model will not only be important for recalibrating existing infrared satellite observation records for climate research applications, but also for the upcoming climate satellite mission FORUM ${ }^{25}$ (Palchetti et al. 2020) and other climate-oriented infrared Earth observing missions, for which absolute radiometric accuracy and stability are crucial. The HIRS data are also very useful for testing and benchmarking asteroid thermal models. Here, the influence of surface roughness and spectral hemispherical emissivity are crucial. In the particular context of short-wavelength near-Earth asteroid measurements, the quality of the derived radiometric properties can be improved. In this work, we demonstrate the impact of spectral emissivity for the determination of the thermal inertia and surface roughness for Ryugu.

Acknowledgements. T.M. and V.A.L. have received funding from the European Union's Horizon 2020 Research and Innovation Programme, under Grant Agreement no. 687378, as part of the project "Small Bodies Near and Far" (SBNAF). M.B. has received funding from the Deutsche Forschungsgemeinschaft, project number 421761264. With this work we contribute to the Cluster of Excellence "CLICCS-Climate, Climatic Change, and Society" funded by the Deutsche Forschungsgemeinschaft DFG (EXC 2037, Project Number 390683824), and to the Center for Earth System Research and Sustainability (CEN) of Universität Hamburg. T.M. also acknowledges the financial support and hospitality of the International Space Science Institute (ISSI) in Bern, Switzerland, which initiated this work by sponsoring and hosting our "ISSI-team" meetings during 2011 to 2014. The level $1 \mathrm{~b}$ files of HIRS were read and processed using Typhon (Lemke et al. 2020)

${ }^{25}$ Far-infrared Outgoing Radiation Understanding and Monitoring.

\section{References}

Alí-Lagoa, V., Müller, T. G., Usui, F., \& Hasegawa, S. 2018, A\&A, 612, A85

Alí-Lagoa, V., Müller, T. G., Kiss, C., et al. 2020, A\&A, 638, A84

Bandfield, J. L., Song, E., Hayne, P. O., et al. 2014, Icarus, 231, 221

Bandfield, J. L., Hayne, P. O., Williams, J.-P., Greenhagen, B. T., \& Paige, D. A 2015, Icarus, 248, 357

Barnes, R. A., Eplee, R. E., Patt, F. S., et al. 2004, Appl. Opt., 43, 5838

Bowell, E., Hapke, B., Domingue, D., et al. 1989, in Asteroids II, eds. R. P. Binzel, T. Gehrels, \& M. S. Matthews (Tucson: University of Arizona Press), 524

Burgdorf, M. J., Buehler, S. A., Hans, I., \& Prange, M. 2019, Adv. Astron., 2350476, 1

Burgdorf, M. J., Müller, T. G., Buehler, S. A., Prange, M., \& Brath, M. 2020, Remote Sens., 12, 1488

Chen, R., \& Cao, C. 2012, J. Geophys. Res., 117, 1

Chen, R., Cao, C., \& Menzel, W. 2013, J. Geophys. Res., 118, 5190

Christensen, P. R., Hamilton, V. E., Mehall, G. L., et al. 2018, Space Sci. Rev., 214, 87

D’Amore, M., Helbert, J., Maturilli, A., et al. 2020, in Europlanet Science Congress 2020, online, EPSC2020-240

Daniels, J., Smith, G., Priestley, K., \& Thomas, S. 2014, Proc. SPIE 9242, 92420X

Davidsson, B. J. R., Rickman, H., Bandfield, J. L., et al. 2015, Icarus, 252, 1

Delbo', M., Dell'Oro, A., Harris, A. W., Mottola, S., \& Mueller, M. 2007, Icarus, 190, 236

Delbo, M., Mueller, M., Emery, J. P., Rozitis, B., \& Capria, M. T. 2015, Asteroid Thermophysical Modeling (Tucson: University of Arizona Press), 107

Detre, Ö. H., Müller, T. G., Klaas, U., et al. 2020, A\&A, 641, A76

Donaldson Hanna, K. L., Wyatt, M. B., Thomas, I. R., et al. 2012, J. Geophys. Res. Planets, 117, E00H05

Glenar, D. A., Stubbs, T. J., Schwieterman, E. W., Robinson, T. D., \& Livengood, T. A. 2019, Icarus, 321, 841

Greenhagen, B. T., Lucey, P. G., Wyatt, M. B., et al. 2010, Science, 329, 1507

Harris, A. W. 1998, Icarus, 131, 291

Harris, A. W., \& Lagerros, J. S. V. 2002, Asteroids III (Tucson: University of Arizona Press), 205

Hayne, P. O., Bandfield, J. L., Siegler, M. A., et al. 2017, J. Geophys. Res. Planets, 122,2371

Helfenstein, P., \& Shepard, M. K. 1999, Icarus, 141, 107

Hill, K., \& Woods, D. 2005, Proc. TEMPMEKO, 2004, 599

Keihm, S. J. 1984, Icarus, 60, 568

Kitazato, K., Milliken, R. E., Iwata, T., et al. 2019, Science, 364, 272

Koenig, E. W. 1980, Performance of the HIRS/2 Instrument on TIROS-N, ed. A. Deepak (New York: Academic Press), 67

Kopp, G., \& Lean, J. L. 2011, Geophys. Res. Lett., 38, L01706

Krotikov, V. D., \& Troitskii, V. S. 1964, Sov. Phys. Uspekhi, 6, 841

Labrot, T., Lavanant, L., Whyte, K., Atkinson, N., \& Brunel, P. 2019, Document NWPSAF-MF-UD-001, V8.1 (available from https://www.nwpsaf. eu/site/software/aapp/documentation/)

Lagerros, J. S. V. 1996, A\&A, 310, 1011

Lagerros, J. S. V. 1997, A\&A, 325, 1226

Lagerros, J. S. V. 1998, A\&A, 332, 1123

Lang, K. 2012, Astrophysical Data: Planets and Stars (New York: Springer)

Lauretta, D. S., Balram-Knutson, S. S., Beshore, E., et al. 2017, Space Sci. Rev., 212,925

Lemke, O., Kluft, L., Mrziglod, J., et al. 2020, atmtools/typhon: Typhon Release 0.8 .0

Liu, N., \& Jin, Y.-Q. 2020, IEEE Trans. Geosci. Remote Sens., 1, 2

Maghrabi, A. H. 2014, Adva. Space Res., 53, 339

Mahoney, W. A., Garcia, L. J., Hunt, J., J., et al. 2010, SPIE Conf. Ser., 7737, 1

Mainzer, A., Grav, T., Masiero, J., et al. 2011, ApJ, 736, 100

Mainzer, A., Bauer, J., Cutri, R. M., et al. 2014, ApJ, 792, 30

Mainzer, A., Usui, F., \& Trilling, D. E. 2015, Space-Based Thermal Infrared Studies of Asteroids (Tucson: University of Arizona Press), 89

Mainzer, A. K., Bauer, J. M., Cutri, R. M., et al. 2016, NASA Planetary Data System, 247

Masiero, J. R., Wright, E. L., \& Mainzer, A. K. 2021, Planet. Sci. J., 2, 32

Matthews, G. 2008, Appl. Opt., 47, 4981

Mommert, M., Jedicke, R., \& Trilling, D. E. 2018, AJ, 155, 74

Moskovitz, N. A., Polishook, D., DeMeo, F. E., et al. 2017, Icarus, 284, 97

Muinonen, K., Belskaya, I. N., Cellino, A., et al. 2010, Icarus, 209, 542

Müller, T. G. 2002, Meteorit. Planet. Sci., 37, 1919

Müller, T. G., \& Lagerros, J. S. V. 1998, A\&A, 338, 340

Müller, T. G., \& Lagerros, J. S. V. 2002, A\&A, 381, 324

Müller, T. G., Durech, J., Hasegawa, S., et al. 2011, A\&A, 525, A145 
T. G. Müller et al.: Benchmarking the asteroid TPM against the Moon

Müller, T., Balog, Z., Nielbock, M., et al. 2014a, Exp. Astron., 37, 253

Müller, T. G., Hasegawa, S., \& Usui, F. 2014b, PASJ, 66, 52

Müller, T. G., Kiss, C., Scheirich, P., et al. 2014c, A\&A, 566, A22

Müller, T. G., Durech, J., Ishiguro, M., et al. 2017, A\&A, 599, A103

Müller, T. G., Marciniak, A., Kiss, C., et al. 2018, Adv. Space Res., 62, 2326

Müller, T., Kiss, C., Ali-Lagoa, V., et al. 2019, Icarus, 334, 39

Müller, T., Lellouch, E., \& Fornasier, S. 2020, Trans-Neptunian Objects and Centaurs at Thermal Wavelengths, eds. D. Prialnik, M. A. Barucci, \& L. Young (Amsterdam: Elsevier), 153

Murcray, F. H., Murcray, D. G., \& Williams, W. J. 1970, J. Geophys. Res., 75, 2662

Myhrvold, N. 2018, Icarus, 303, 91

Okada, T., Fukuhara, T., Tanaka, S., et al. 2017, Space Sci. Rev., 208, 255

Okada, T., Fukuhara, T., Tanaka, S., et al. 2018, Planet. Space Sci., 158, 46

Okada, T., Fukuhara, T., Tanaka, S., et al. 2020, Nature, 579, 518

Ortiz, J. L., Sicardy, B., Camargo, J. I. B., Santos-Sanz, P., \& Braga-Ribas, F. 2020, Stellar Occultation by TNOs: from Predictions to Observations, eds. D. Prialnik, M. A. Barucci, \& L. Young (Amsterdam: Elsevier), 413

Ostro, S. J. 1993, Rev. Mod. Phys., 65, 1235

Paige, D. A., Foote, M. C., Greenhagen, B. T., et al. 2010, Space Sci. Rev., 150, 125

Palchetti, L., Brindley, H., Bantges, R., et al. 2020, Bull. Am. Meteor. Soc., 101, 12

Rosenburg, M. A., Aharonson, O., Head, J. W., et al. 2011, J. Geophys. Res. Planets, 116, E02001

Rozitis, B., \& Green, S. F. 2011, MNRAS, 415, 2042

Rubanenko, L., Schorghofer, N., Greenhagen, B. T., \& Paige, D. A. 2020, J. Geophys. Res. Planets, 125, e06377
Saari, J. M., \& Shorthill, R. W. 1972, Moon, 5, 161

Salisbury, J. W., Basu, A., \& Fischer, E. M. 1997, Icarus, 130, 125

Saunders, P. 2013, AIP Conf. Proc., 1552, 619

Shimaki, Y., Senshu, H., Sakatani, N., et al. 2020, Icarus, 348, 113835

Simon, A. A., Donaldson Hanna, K. L., Drouet d'Aubigny, C. Y., et al. 2019 Geophys. Res. Lett., 46, 6322

Sinto, W. M. 1962, Temperatures on the Lunar Surface, ed. Z. Kopal (New York: Academic Press), 407

Spencer, J. R. 1990, Icarus, 83, 27

Spencer, J. R., Lebofsky, L. A., \& Sykes, M. V. 1989, Icarus, 78, 337

Stansberry, J., Grundy, W., Brown, M., et al. 2008, Physical Properties of Kuiper Belt and Centaur Objects: Constraints from the Spitzer Space Telescope, eds. M. A. Barucci, H. Boehnhardt, D. P. Cruikshank, A. Morbidelli, \& R. Dotson (Tucson: University of Arizona Press), 161

Sugita, S., Honda, R., Morota, T., et al. 2019, Science, 364, 252

Tedesco, E. F., Noah, P. V., Noah, M., \& Price, S. D. 2002a, AJ, 123, 1056

Tedesco, E. F., Egan, M. P., \& Price, S. D. 2002b, AJ, 124, 583

Tsuda, Y., Nakazawa, S., Kushiki, K., et al. 2016, Acta Astron., 127, 702

Usui, F., Kuroda, D., Müller, T. G., et al. 2011, PASJ, 63, 1117

Usui, F., Kasuga, T., Hasegawa, S., et al. 2013, ApJ, 762, 56

Usui, F., Hasegawa, S., Ishiguro, M., Müller, T. G., \& Ootsubo, T. 2014, PASJ, 66,56

Vasavada, A. R., Bandfield, J. L., Greenhagen, B. T., et al. 2012, J. Geophys. Res. Planets, 117, H18

Watanabe, S., Hirabayashi, M., Hirata, N., et al. 2019, Science, 364, 268

Wolters, S. D., \& Green, S. F. 2009, MNRAS, 400, 204

Wright, E., Mainzer, A., Masiero, J., et al. 2018, ArXiv e-prints [arXiv:1811.01454] 


\section{Appendix A: Thermal-IR HIRS measurements of the Moon}

We list the extracted and derived HIRS Moon values in the following tables. Tables A.1-A.3 list the calibrated radiances $(\operatorname{Rad})$ and brightness temperatures $\left(T_{\mathrm{b}}\right)$ of the Moon for the long-wavelength channels 1-6, 7-12 and the short-wavelength channels 13-19, respectively. Due to the unknown contribution of reflected sunlight in channels 17 and 18 , there were no brightness temperatures calculated in these two channels.

The disk-integrated flux densities (in Jansky) were calculated from the radiance values and the apparent cross-section of the Moon at the time of the observation and as seen from the particular satellite. Tables A.4 and A.5 contain all crucial values for the long-wavelength channels 1-12 and the short-wavelength channels $13-19$, respectively.

The "Observation epoch" data and time entries are taken from the coordinate "time" in the level $1 \mathrm{~b}$ data file. We added $3.2 \mathrm{sec}$ to this value, to give the time of the middle of the scan instead of its start. The HIRS scans were manually inspected to identify the range of scan positions, where the signal in the DSV was constant. This is the case if and only if the Moon is fully included in the FOV or not present at all. A few cases where the visual inspection left some doubt are labeled with footnotes in Table 1, that is, the measured flux is only a lower limit. These limits, however, are always rather close to the real value. Details on all detections can all be provided on request, including the range of scan positions, mean counts from the DSV with the Moon included (as well as $256 \mathrm{sec}$ before and after during the calibration configurations), the standard deviation of the counts, the mean temperatures of the internal warm calibrator target from level $1 \mathrm{~b}$ data (five temperatures for HIRS/2 and HIRS/3, and six temperatures for HIRS/4), and the fitted blackbody radiances and slopes.

The radiance values of the Moon were calculated with a twopoint calibration using "slope" and Moon-DSV differences, then divided by the fraction of the FOV filled by the Moon and the beam efficiency (Koenig 1980, and User's Guide ${ }^{26}$ ). Its $\sigma$ was calculated with the error propagation from the counts, assuming that the error of the BB Temp is zero. The "brightness temperatures" are derived from the radiance via the inverse Planck function at the specified wavelength ${ }^{27}$. We used the shifted relative spectral response functions. The FOV diameters, assumed in the calculation of radiance, were taken from the OSCAR web page and confirmed via the JPL/Horizons system (see also Sect. 2).

\footnotetext{
${ }^{26}$ https://archive.org/details/noaa-klm-guide/page/n5/ mode/2up

27 The central wavelength of the channels are given on the web page https://www.nwpsaf.eu/site/software/rttov/download/ coefficients/spectral-response-functions/
} 
T. G. Müller et al.: Benchmarking the asteroid TPM against the Moon

\section{A.1. Calibrated Radiances and brightness temperatures}

Table A.1. Calibrated Radiances (Rad) and brightness temperatures $\left(T_{\mathrm{b}}\right)$ of the Moon for the long-wavelength channels 1-6.

\begin{tabular}{|c|c|c|c|c|c|c|c|c|c|c|c|c|}
\hline \multirow{2}{*}{$\begin{array}{l}\text { Satellite/Instrument } \\
\text { Observation epoch }\end{array}$} & \multicolumn{2}{|l|}{$\lambda_{\mathrm{ch} 01}$} & \multicolumn{2}{|l|}{$\lambda_{\text {ch02 }}$} & \multicolumn{2}{|l|}{$\lambda_{\text {ch03 }}$} & \multicolumn{2}{|l|}{$\lambda_{\text {ch04 }}$} & \multicolumn{2}{|l|}{$\lambda_{\mathrm{ch} 05}$} & \multicolumn{2}{|l|}{$\lambda_{\text {ch06 }}$} \\
\hline & $\operatorname{Rad}\left[\mathrm{MJy} \mathrm{sr}^{-1}\right]$ & $T_{\mathrm{b}}[\mathrm{K}]$ & $\operatorname{Rad}\left[\mathrm{MJy} \mathrm{sr}^{-1}\right]$ & $T_{\mathrm{b}}[\mathrm{K}]$ & $\operatorname{Rad}\left[\mathrm{MJy} \mathrm{sr}^{-1}\right]$ & $T_{\mathrm{b}}[\mathrm{K}]$ & $\operatorname{Rad}\left[\mathrm{MJy} \mathrm{sr}^{-1}\right]$ & $T_{\mathrm{b}}[\mathrm{K}]$ & $\operatorname{Rad}\left[\mathrm{MJy} \mathrm{sr}^{-1}\right]$ & $T_{\mathrm{b}}[\mathrm{K}]$ & $\operatorname{Rad}\left[\mathrm{MJy} \mathrm{sr}^{-1}\right]$ & $T_{\mathrm{b}}[\mathrm{K}]$ \\
\hline NOAA-11/HIRS2 & 14.852 & & 14.731 & & 14.488 & & 14.183 & & 13.909 & & 13.658 & \\
\hline 1993-11-25 17:39:34 & $7.0029 \mathrm{E}+08$ & 333.1 & $7.1973 \mathrm{E}+08$ & 336.2 & $7.1915 \mathrm{E}+08$ & 336.3 & $7.1057 \mathrm{E}+08$ & 335.3 & $6.9957 \mathrm{E}+08$ & 334.1 & $6.9930 \mathrm{E}+08$ & 334.6 \\
\hline 1992-02-15 19:54:15 & $7.4778 \mathrm{E}+08$ & 340.4 & $7.7230 \mathrm{E}+08$ & 344.1 & $7.7500 \mathrm{E}+08$ & 344.5 & $7.6403 \mathrm{E}+08$ & 343.1 & $7.5399 \mathrm{E}+08$ & 342.0 & $7.5797 \mathrm{E}+08$ & 343.0 \\
\hline 1990-11-27 05:04:49 & $4.0605 \mathrm{E}+08$ & 282.5 & $4.1279 \mathrm{E}+08$ & 284.1 & $4.1873 \mathrm{E}+08$ & 286.0 & $4.0885 \mathrm{E}+08$ & 285.2 & $4.0393 \mathrm{E}+08$ & 285.3 & $4.0205 \mathrm{E}+08$ & 286.0 \\
\hline 1989-03-17 03:31:08 & $5.0036 \mathrm{E}+08$ & 300.1 & $5.2402 \mathrm{E}+08$ & 304.5 & $5.3369 \mathrm{E}+08$ & 306.7 & $5.2788 \mathrm{E}+08$ & 306.5 & $5.2205 \mathrm{E}+08$ & 306.3 & $5.2341 \mathrm{E}+08$ & 307.4 \\
\hline NOAA-14/HIRS2 & 14.955 & & 14.701 & & 14.487 & & 14.171 & & 13.931 & & 13.656 & \\
\hline 2000-04-14 10:50:44 & $5.5529 \mathrm{E}+08$ & 309.4 & $5.6072 \mathrm{E}+08$ & 310.9 & $5.6217 \mathrm{E}+08$ & 311.5 & $5.6149 \mathrm{E}+08$ & 312.1 & $5.6476 \mathrm{E}+08$ & 313.3 & $5.6277 \mathrm{E}+08$ & 313.8 \\
\hline 1997-12-08 21:52:12 & $4.1319 \mathrm{E}+08$ & 283.6 & $4.1789 \mathrm{E}+08$ & 285.2 & $4.2159 \mathrm{E}+08$ & 286.6 & $4.1879 \mathrm{E}+08$ & 287.1 & $4.2175 \mathrm{E}+08$ & 288.6 & $4.2141 \mathrm{E}+08$ & 289.6 \\
\hline 1997-06-15 05:05:20 & $3.7208 \mathrm{E}+08$ & 275.5 & $3.9263 \mathrm{E}+08$ & 280.2 & $3.9936 \mathrm{E}+08$ & 282.3 & $3.9579 \mathrm{E}+08$ & 282.7 & $3.9949 \mathrm{E}+08$ & 284.4 & $4.0078 \mathrm{E}+08$ & 285.8 \\
\hline 1996-10-23 00:30:08 & $6.3513 \mathrm{E}+08$ & 322.8 & $6.2982 \mathrm{E}+08$ & 322.2 & $6.3101 \mathrm{E}+08$ & 322.7 & $6.3170 \mathrm{E}+08$ & 323.4 & $6.3456 \mathrm{E}+08$ & 324.3 & $6.3426 \mathrm{E}+08$ & 324.9 \\
\hline 1996-05-28 20:58:58 & $5.7402 \mathrm{E}+08$ & 312.6 & $5.5256 \mathrm{E}+08$ & 309.5 & $5.5147 \mathrm{E}+08$ & 309.7 & $5.5032 \mathrm{E}+08$ & 310.3 & $5.5267 \mathrm{E}+08$ & 311.3 & $5.5170 \mathrm{E}+08$ & 312.0 \\
\hline 1995-12-03 07:13:24 & $6.9262 \mathrm{E}+08$ & 331.9 & $6.9824 \mathrm{E}+08$ & 332.9 & $7.0785 \mathrm{E}+08$ & 334.5 & $7.0848 \mathrm{E}+08$ & 335.0 & $7.1355 \mathrm{E}+08$ & 336.1 & $7.1490 \mathrm{E}+08$ & 336.8 \\
\hline NOAA-15/HIRS3 & 14.976 & & 14.743 & & 14.508 & & 14.226 & & 13.963 & & 13.666 & \\
\hline 2019-12-14 09:47:24 & $\mathrm{NaN}$ & $\mathrm{NaN}$ & $\mathrm{NaN}$ & $\mathrm{NaN}$ & $\mathrm{NaN}$ & $\mathrm{NaN}$ & $\mathrm{NaN}$ & $\mathrm{NaN}$ & $\mathrm{NaN}$ & $\mathrm{NaN}$ & $\mathrm{NaN}$ & $\mathrm{NaN}$ \\
\hline 2018-12-24 11:44:46 & $7.9469 \mathrm{E}+08$ & 347.5 & $8.0152 \mathrm{E}+08$ & 348.4 & $8.0158 \mathrm{E}+08$ & 348.4 & $8.0388 \mathrm{E}+08$ & 348.8 & $8.0714 \mathrm{E}+08$ & 349.5 & $8.0785 \mathrm{E}+08$ & 349.9 \\
\hline NOAA-17/HIRS3 & 14.966 & & 14.669 & & 14.474 & & 14.219 & & 13.958 & & 13.664 & \\
\hline 2003-01-24 01:20:02 & $3.4799 \mathrm{E}+08$ & 270.4 & $3.5665 \mathrm{E}+08$ & 273.2 & $3.5572 \mathrm{E}+08$ & 273.6 & $3.6154 \mathrm{E}+08$ & 275.8 & $3.5885 \mathrm{E}+08$ & 276.3 & $3.5869 \mathrm{E}+08$ & 277.6 \\
\hline 2002-09-26 07:01:22 & $4.9181 \mathrm{E}+08$ & 298.0 & $5.1313 \mathrm{E}+08$ & 302.9 & $5.2349 \mathrm{E}+08$ & 304.9 & $5.3267 \mathrm{E}+08$ & 307.2 & $5.3600 \mathrm{E}+08$ & 308.5 & $5.4329 \mathrm{E}+08$ & 310.6 \\
\hline NOAA-18/HIRS4 & 14.980 & & 14.697 & & 14.513 & & 14.223 & & 14.006 & & 13.670 & \\
\hline 2018-11-26 17:59:54 & $5.9202 \mathrm{E}+08$ & 315.7 & $6.1874 \mathrm{E}+08$ & 320.4 & $6.2177 \mathrm{E}+08$ & 321.2 & $6.2056 \mathrm{E}+08$ & 321.5 & $6.1958 \mathrm{E}+08$ & 321.8 & $6.1922 \mathrm{E}+08$ & 322.6 \\
\hline 2018-04-02 09:27:54 & $7.8316 \mathrm{E}+08$ & 345.7 & $7.9485 \mathrm{E}+08$ & 347.4 & $7.9684 \mathrm{E}+08$ & 347.7 & $7.9588 \mathrm{E}+08$ & 347.7 & $7.9542 \mathrm{E}+08$ & 347.8 & $7.9757 \mathrm{E}+08$ & 348.5 \\
\hline 2011-03-14 10:32:05 & $3.6979 \mathrm{E}+08$ & 274.8 & $3.6765 \mathrm{E}+08$ & 275.3 & $3.6765 \mathrm{E}+08$ & 275.9 & $3.6543 \mathrm{E}+08$ & 276.5 & $3.6336 \mathrm{E}+08$ & 277.0 & $3.6302 \mathrm{E}+08$ & 278.4 \\
\hline NOAA-19/HIRS4 & 14.953 & & 14.685 & & 14.526 & & 14.232 & & 13.973 & & 13.635 & \\
\hline 2017-12-02 12:50:03 & $8.7728 \mathrm{E}+08$ & 359.4 & $8.7793 \mathrm{E}+08$ & 359.3 & $8.7801 \mathrm{E}+08$ & 359.2 & $8.7378 \mathrm{E}+08$ & 358.5 & $8.7204 \mathrm{E}+08$ & 358.4 & $8.7601 \mathrm{E}+08$ & 359.1 \\
\hline 2012-03-04 05:07:04 & $\mathrm{NaN}$ & $\mathrm{NaN}$ & $\mathrm{NaN}$ & $\mathrm{NaN}$ & $\mathrm{NaN}$ & $\mathrm{NaN}$ & $\mathrm{NaN}$ & $\mathrm{NaN}$ & $\mathrm{NaN}$ & $\mathrm{NaN}$ & $\mathrm{NaN}$ & $\mathrm{NaN}$ \\
\hline MetOp-A/HIRS4 & 14.955 & & 14.719 & & 14.503 & & 14.248 & & 13.955 & & 13.667 & \\
\hline 2011-11-16 23:42:26 & $3.8160 \mathrm{E}+08$ & 277.3 & $3.8498 \mathrm{E}+08$ & 278.7 & $3.8664 \mathrm{E}+08$ & 279.7 & $3.8605 \mathrm{E}+08$ & 280.5 & $3.8720 \mathrm{E}+08$ & 281.9 & $3.8538 \mathrm{E}+08$ & 282.8 \\
\hline MetOp-B/HIRS4 & 14.964 & & 14.688 & & 14.474 & & 14.248 & & 13.996 & & 13.671 & \\
\hline 2019-07-21 07:57:26 & $5.9845 \mathrm{E}+08$ & 319.0 & $6.0140 \mathrm{E}+08$ & 319.9 & $5.9840 \mathrm{E}+08$ & 319.8 & $5.9717 \mathrm{E}+08$ & 320.0 & $5.9315 \mathrm{E}+08$ & 319.9 & $5.9208 \mathrm{E}+08$ & 320.6 \\
\hline 2015-02-07 05:12:40 & $7.7175 \mathrm{E}+08$ & 344.0 & $7.6936 \mathrm{E}+08$ & 343.6 & $7.6997 \mathrm{E}+08$ & 343.8 & $7.6840 \mathrm{E}+08$ & 343.7 & $7.6449 \mathrm{E}+08$ & 343.4 & $7.6443 \mathrm{E}+08$ & 343.8 \\
\hline
\end{tabular}


A\&A 650, A38 (2021)

Table A.2. Calibrated Radiances and brightness temperatures of the Moon for the long-wavelength channels 7-12.

\begin{tabular}{|c|c|c|c|c|c|c|c|c|c|c|c|c|}
\hline \multirow{2}{*}{$\begin{array}{l}\text { Satellite/Instrument } \\
\text { Observation epoch }\end{array}$} & \multicolumn{2}{|l|}{$\lambda_{\mathrm{ch} 07}$} & \multicolumn{2}{|l|}{$\lambda_{\operatorname{ch} 08}$} & \multicolumn{2}{|l|}{$\lambda_{\mathrm{ch} 09}$} & \multicolumn{2}{|l|}{$\lambda_{\operatorname{ch} 10}$} & \multicolumn{2}{|l|}{$\lambda_{\operatorname{ch} 11}$} & \multicolumn{2}{|l|}{$\lambda_{\mathrm{ch} 12}[\mu \mathrm{m}]$} \\
\hline & $\operatorname{Rad}\left[\mathrm{MJy} \mathrm{sr}^{-1}\right]$ & $T_{\mathrm{b}}[\mathrm{K}]$ & $\operatorname{Rad}\left[\mathrm{MJy} \mathrm{sr}^{-1}\right]$ & $T_{\mathrm{b}}[\mathrm{K}]$ & $\operatorname{Rad}\left[\mathrm{MJy} \mathrm{sr}^{-1}\right]$ & $T_{\mathrm{b}}[\mathrm{K}]$ & $\operatorname{Rad}\left[\mathrm{MJy} \mathrm{sr}^{-1}\right]$ & $T_{\mathrm{b}}[\mathrm{K}]$ & $\operatorname{Rad}\left[\mathrm{MJy} \mathrm{sr}^{-1}\right.$ ] & $T_{\mathrm{b}}[\mathrm{K}]$ & $\operatorname{Rad}\left[\mathrm{MJy} \mathrm{sr}^{-1}\right]$ & $T_{\mathrm{b}}[\mathrm{K}]$ \\
\hline NOAA-11/HIRS2 & 13.340 & & 11.088 & & 9.733 & & 12.565 & & 7.362 & & 6.738 & \\
\hline 1993-11-25 17:39:34 & $6.9877 \mathrm{E}+08$ & 335.3 & $6.3100 \mathrm{E}+08$ & 336.7 & $5.6741 \mathrm{E}+08$ & 340.4 & $6.8019 \mathrm{E}+08$ & 335.2 & $3.2155 \mathrm{E}+08$ & 340.5 & $2.4419 \mathrm{E}+08$ & 340.1 \\
\hline 1992-02-15 19:54:15 & $7.5477 \mathrm{E}+08$ & 343.2 & $6.8889 \mathrm{E}+08$ & 344.3 & $6.2065 \mathrm{E}+08$ & 347.5 & 7.3917E+08 & 343.3 & $3.5250 \mathrm{E}+08$ & 346.1 & $2.6775 \mathrm{E}+08$ & 345.2 \\
\hline 1990-11-27 05:04:49 & $4.0074 \mathrm{E}+08$ & 287.2 & $3.5113 \mathrm{E}+08$ & 292.9 & $3.0803 \mathrm{E}+08$ & 298.8 & $3.8745 \mathrm{E}+08$ & 288.8 & $1.6844 \mathrm{E}+08$ & 306.1 & $1.2428 \mathrm{E}+08$ & 307.1 \\
\hline 1989-03-17 03:31:08 & $5.1980 \mathrm{E}+08$ & 307.9 & $4.6747 \mathrm{E}+08$ & 312.8 & 4.1497E+08 & 317.7 & $5.0691 \mathrm{E}+08$ & 309.3 & $2.3004 \mathrm{E}+08$ & 321.8 & $1.7181 \mathrm{E}+08$ & 322.1 \\
\hline NOAA-14/HIRS2 & 13.317 & & 11.119 & & 9.725 & & 12.508 & & 7.398 & & 6.733 & \\
\hline 2000-04-14 10:50:44 & $5.5863 \mathrm{E}+08$ & 314.3 & $4.9360 \mathrm{E}+08$ & 316.6 & $4.2576 \mathrm{E}+08$ & 319.6 & $5.4063 \mathrm{E}+08$ & 315.0 & $2.4988 \mathrm{E}+08$ & 325.4 & $1.8643 \mathrm{E}+08$ & 326.2 \\
\hline $1997-12-08$ 21:52:12 & $4.1836 \mathrm{E}+08$ & 290.5 & $3.6626 \mathrm{E}+08$ & 295.4 & $3.1360 \mathrm{E}+08$ & 299.9 & $4.0375 \mathrm{E}+08$ & 292.1 & $1.8165 \mathrm{E}+08$ & 309.0 & $1.3416 \mathrm{E}+08$ & 310.7 \\
\hline $1997-06-15$ 05:05:20 & $3.9883 \mathrm{E}+08$ & 286.9 & $3.5284 \mathrm{E}+08$ & 292.9 & $3.0265 \mathrm{E}+08$ & 297.8 & $3.8658 \mathrm{E}+08$ & 289.0 & $1.7057 \mathrm{E}+08$ & 305.9 & $1.2469 \mathrm{E}+08$ & 307.4 \\
\hline 1996-10-23 00:30:08 & $6.2580 \mathrm{E}+08$ & 324.6 & $5.6161 \mathrm{E}+08$ & 326.7 & $4.9236 \mathrm{E}+08$ & 329.8 & $6.0748 \mathrm{E}+08$ & 325.1 & $2.8655 \mathrm{E}+08$ & 333.1 & $2.1521 E+08$ & 333.5 \\
\hline $1996-05-28$ 20:58:58 & $5.4208 \mathrm{E}+08$ & 311.7 & $4.8369 \mathrm{E}+08$ & 315.1 & 4.2213E+08 & 319.0 & $5.2410 \mathrm{E}+08$ & 312.4 & $2.4065 \mathrm{E}+08$ & 323.4 & $1.7826 \mathrm{E}+08$ & 324.0 \\
\hline $1995-12-03$ 07:13:24 & $7.1163 \mathrm{E}+08$ & 337.2 & $6.4413 \mathrm{E}+08$ & 338.2 & $5.6498 \mathrm{E}+08$ & 340.1 & $6.9442 \mathrm{E}+08$ & 337.4 & $3.3636 \mathrm{E}+08$ & 342.4 & $2.5264 \mathrm{E}+08$ & 342.1 \\
\hline NOAA-15/HIRS3 & 13.357 & & 11.151 & & 9.705 & & 12.444 & & 7.303 & & 6.534 & \\
\hline $2019-12-1409: 47: 24$ & $\mathrm{NaN}$ & $\mathrm{NaN}$ & $\mathrm{NaN}$ & $\mathrm{NaN}$ & $\mathrm{NaN}$ & $\mathrm{NaN}$ & $\mathrm{NaN}$ & $\mathrm{NaN}$ & $\mathrm{NaN}$ & $\mathrm{NaN}$ & $\mathrm{NaN}$ & $\mathrm{NaN}$ \\
\hline $2018-12-24$ 11:44:46 & $8.0037 \mathrm{E}+08$ & 349.4 & $7.4721 \mathrm{E}+08$ & 351.4 & $6.1546 \mathrm{E}+08$ & 347.1 & $7.9463 \mathrm{E}+08$ & 351.0 & $3.6596 \mathrm{E}+08$ & 349.7 & $2.6748 \mathrm{E}+08$ & 350.7 \\
\hline NOAA-17/HIRS3 & 13.360 & & 11.123 & & 9.722 & & 12.430 & & 7.320 & & 6.547 & \\
\hline 2003-01-24 01:20:02 & $3.5210 \mathrm{E}+08$ & 277.7 & $3.0859 \mathrm{E}+08$ & 284.3 & $2.4552 \mathrm{E}+08$ & 285.9 & $3.4399 \mathrm{E}+08$ & 281.4 & $1.3770 \mathrm{E}+08$ & 297.7 & $9.5449 \mathrm{E}+07$ & 301.0 \\
\hline $2002-09-26$ 07:01:22 & $5.4271 \mathrm{E}+08$ & 311.6 & $5.0553 \mathrm{E}+08$ & 318.4 & $4.2115 \mathrm{E}+08$ & 318.9 & $5.3860 \mathrm{E}+08$ & 315.0 & $2.3880 \mathrm{E}+08$ & 324.7 & $1.6790 \mathrm{E}+08$ & 326.1 \\
\hline NOAA-18/HIRS4 & 13.340 & & 11.117 & & 9.720 & & 12.501 & & 7.314 & & 6.513 & \\
\hline $2018-11-26$ 17:59:54 & $6.2009 \mathrm{E}+08$ & 323.7 & $5.6910 \mathrm{E}+08$ & 327.9 & $5.0252 \mathrm{E}+08$ & 331.4 & $6.1069 \mathrm{E}+08$ & 325.6 & $2.8894 \mathrm{E}+08$ & 335.4 & $2.0179 \mathrm{E}+08$ & 336.2 \\
\hline 2018-04-02 09:27:54 & $8.0212 \mathrm{E}+08$ & 349.6 & $7.4147 \mathrm{E}+08$ & 350.8 & $6.6170 \mathrm{E}+08$ & 352.8 & $7.9098 \mathrm{E}+08$ & 350.4 & $3.8039 \mathrm{E}+08$ & 351.9 & $2.6473 \mathrm{E}+08$ & 350.7 \\
\hline 2011-03-14 10:32:05 & $3.6310 \mathrm{E}+08$ & 280.0 & $3.1963 \mathrm{E}+08$ & 286.6 & $2.7418 \mathrm{E}+08$ & 292.1 & $3.5296 \mathrm{E}+08$ & 282.7 & $1.5047 \mathrm{E}+08$ & 301.9 & $1.0074 \mathrm{E}+08$ & 304.1 \\
\hline NOAA-19/HIRS4 & 13.347 & & 11.124 & & 9.729 & & 12.456 & & 7.352 & & 6.529 & \\
\hline $2017-12-02$ 12:50:03 & $8.7990 \mathrm{E}+08$ & 359.9 & $8.1692 \mathrm{E}+08$ & 360.0 & $7.3541 \mathrm{E}+08$ & 361.7 & $8.7290 \mathrm{E}+08$ & 360.9 & $4.3089 \mathrm{E}+08$ & 359.0 & $3.0001 \mathrm{E}+08$ & 357.3 \\
\hline 2012-03-04 05:07:04 & $\mathrm{NaN}$ & $\mathrm{NaN}$ & $\mathrm{NaN}$ & $\mathrm{NaN}$ & $\mathrm{NaN}$ & $\mathrm{NaN}$ & $\mathrm{NaN}$ & $\mathrm{NaN}$ & $\mathrm{NaN}$ & $\mathrm{NaN}$ & $\mathrm{NaN}$ & $\mathrm{NaN}$ \\
\hline MetOp-A/HIRS4 & 13.354 & & 11.129 & & 9.723 & & 12.486 & & 7.343 & & 6.536 & \\
\hline 2011-11-16 23:42:26 & $3.8384 \mathrm{E}+08$ & 283.9 & $3.4381 \mathrm{E}+08$ & 291.1 & $2.9640 \mathrm{E}+08$ & 296.6 & $3.7100 \mathrm{E}+08$ & 286.6 & $1.6563 \mathrm{E}+08$ & 305.8 & $1.1339 \mathrm{E}+08$ & 308.8 \\
\hline MetOp-B/HIRS4 & 13.390 & & 11.127 & & 9.715 & & 12.438 & & 7.355 & & 6.521 & \\
\hline 2019-07-21 07:57:26 & $5.9359 \mathrm{E}+08$ & 321.6 & $5.3386 \mathrm{E}+08$ & 324.5 & 4.6917E+08 & 328.1 & $5.8126 \mathrm{E}+08$ & 323.5 & $2.6547 \mathrm{E}+08$ & 331.0 & $1.8268 \mathrm{E}+08$ & 332.1 \\
\hline 2015-02-07 05:12:40 & $7.6711 \mathrm{E}+08$ & 344.7 & $7.0041 \mathrm{E}+08$ & 345.6 & $6.2470 \mathrm{E}+08$ & 348.2 & $7.5540 \mathrm{E}+08$ & 345.9 & $3.6176 \mathrm{E}+08$ & 347.8 & $2.5389 \mathrm{E}+08$ & 348.2 \\
\hline
\end{tabular}


T. G. Müller et al.: Benchmarking the asteroid TPM against the Moon

Table A.3. Calibrated Radiances and brightness temperatures of the Moon for the short-wavelength channels 13-19.

\begin{tabular}{|c|c|c|c|c|c|c|c|c|c|c|c|c|}
\hline \multirow{2}{*}{$\begin{array}{l}\text { Satellite/Instrument } \\
\text { Observation epoch }\end{array}$} & \multicolumn{2}{|l|}{$\lambda_{\mathrm{ch} 13}$} & \multicolumn{2}{|l|}{$\lambda_{\operatorname{ch} 14}$} & \multicolumn{2}{|l|}{$\lambda_{\mathrm{ch} 15}$} & \multicolumn{2}{|l|}{$\lambda_{\mathrm{ch} 16}$} & \multicolumn{2}{|l|}{$\lambda_{\operatorname{ch} 17}$} & \multirow{2}{*}{$\begin{array}{c}\lambda_{\text {ch18 }} \\
\operatorname{Rad}\left[\mathrm{MJy} \mathrm{sr}^{-1}\right]\end{array}$} & \multirow{2}{*}{$\begin{array}{c}\lambda_{\operatorname{ch} 19}[\mu \mathrm{m}] \\
\operatorname{Rad}\left[\mathrm{MJy} \mathrm{sr}^{-1}\right]\end{array}$} \\
\hline & $\operatorname{Rad}\left[\mathrm{MJy} \mathrm{sr}^{-1}\right]$ & $T_{\mathrm{b}}[\mathrm{K}]$ & $\operatorname{Rad}\left[\mathrm{MJy} \mathrm{sr}^{-1}\right]$ & $T_{\mathrm{b}}[\mathrm{K}]$ & $\operatorname{Rad}\left[\mathrm{MJy} \mathrm{sr}^{-1}\right]$ & $T_{\mathrm{b}}[\mathrm{K}]$ & $\operatorname{Rad}\left[\mathrm{MJy} \mathrm{sr}^{-1}\right]$ & $T_{\mathrm{b}}[\mathrm{K}]$ & $\operatorname{Rad}\left[\mathrm{MJy} \mathrm{sr}^{-1}\right]$ & $T_{\mathrm{b}}[\mathrm{K}]$ & & \\
\hline NOAA-11/HIRS2 & 4.566 & & 4.525 & & 4.466 & & 4.409 & & 4.138 & & 3.981 & 3.753 \\
\hline 1993-11-25 17:39 & $4.4544 \mathrm{E}+07$ & 344.6 & $4.2184 \mathrm{E}+07$ & 344.6 & $3.9387 \mathrm{E}+07$ & 345.1 & $3.7092 \mathrm{E}+07$ & 345.9 & $2.6219 \mathrm{E}+07$ & 348.7 & $2.1502 \mathrm{E}+07$ & $1.5759 \mathrm{E}+07$ \\
\hline 1992-02-15 19:54 & $\mathrm{NaN}$ & $\mathrm{NaN}$ & $\mathrm{NaN}$ & $\mathrm{NaN}$ & $\mathrm{NaN}$ & $\mathrm{NaN}$ & $\mathrm{NaN}$ & $\mathrm{NaN}$ & $2.8494 \mathrm{E}+07$ & 351.7 & $\mathrm{NaN}$ & $\mathrm{NaN}$ \\
\hline 1990-11-27 05:04 & $\mathrm{NaN}$ & $\mathrm{NaN}$ & $\mathrm{NaN}$ & $\mathrm{NaN}$ & $\mathrm{NaN}$ & $\mathrm{NaN}$ & $\mathrm{NaN}$ & $\mathrm{NaN}$ & $1.1669 \mathrm{E}+07$ & 322.5 & $\mathrm{NaN}$ & $\mathrm{NaN}$ \\
\hline 1989-03-17 03:31 & $\mathrm{NaN}$ & $\mathrm{NaN}$ & $\mathrm{NaN}$ & $\mathrm{NaN}$ & $\mathrm{NaN}$ & $\mathrm{NaN}$ & $\mathrm{NaN}$ & $\mathrm{NaN}$ & $1.6397 \mathrm{E}+07$ & 333.0 & $\mathrm{NaN}$ & $\mathrm{NaN}$ \\
\hline NOAA-14/HIRS2 & 4.563 & & 4.530 & & 4.472 & & 4.409 & & 4.132 & & 3.980 & 3.776 \\
\hline 2000-04-14 10:50:44 & $3.2097 \mathrm{E}+07$ & 332.8 & $3.0767 \mathrm{E}+07$ & 333.0 & $2.8551 \mathrm{E}+07$ & 333.3 & $2.6388 \mathrm{E}+07$ & 333.9 & $1.8025 \mathrm{E}+07$ & 336.4 & $1.4746 \mathrm{E}+07$ & $1.1002 \mathrm{E}+07$ \\
\hline 1997-12-08 21:52:12 & $2.2330 \mathrm{E}+07$ & 320.5 & $2.1375 \mathrm{E}+07$ & 320.7 & $1.9854 \mathrm{E}+07$ & 321.2 & $1.8307 \mathrm{E}+07$ & 321.8 & $1.2494 \mathrm{E}+07$ & 324.9 & $1.0216 \mathrm{E}+07$ & $7.6185 \mathrm{E}+06$ \\
\hline 1997-06-15 05:05:20 & $1.9721 \mathrm{E}+07$ & 316.5 & $1.9015 \mathrm{E}+07$ & 317.0 & $1.7633 \mathrm{E}+07$ & 317.5 & $1.6281 \mathrm{E}+07$ & 318.2 & $1.1215 \mathrm{E}+07$ & 321.7 & $9.1837 \mathrm{E}+06$ & $6.8734 \mathrm{E}+06$ \\
\hline 1996-10-23 00:30:08 & $3.8316 \mathrm{E}+07$ & 339.1 & $3.6903 \mathrm{E}+07$ & 339.4 & $3.4323 \mathrm{E}+07$ & 339.8 & $3.1810 \mathrm{E}+07$ & 340.4 & $2.2115 \mathrm{E}+07$ & 343.2 & $1.8199 \mathrm{E}+07$ & $1.3676 \mathrm{E}+07$ \\
\hline 1996-05-28 20:58:58 & $3.0631 \mathrm{E}+07$ & 331.2 & $2.9515 \mathrm{E}+07$ & 331.5 & $2.7481 \mathrm{E}+07$ & 332.0 & $2.5460 \mathrm{E}+07$ & 332.7 & $1.7827 \mathrm{E}+07$ & 336.1 & $1.4694 \mathrm{E}+07$ & $1.1107 \mathrm{E}+07$ \\
\hline 1995-12-03 07:13:24 & $4.5724 \mathrm{E}+07$ & 345.7 & 4.3947E+07 & 345.9 & $4.0874 \mathrm{E}+07$ & 346.2 & $3.7817 \mathrm{E}+07$ & 346.6 & $2.6089 \mathrm{E}+07$ & 348.9 & $2.1415 \mathrm{E}+07$ & $1.6047 \mathrm{E}+07$ \\
\hline NOAA-15/HIRS3 & 4.570 & & 4.525 & & 4.474 & & 4.460 & & 4.134 & & 3.970 & 3.763 \\
\hline 2019-12-14 09:47:24 & $\mathrm{NaN}$ & $\mathrm{NaN}$ & $\mathrm{NaN}$ & $\mathrm{NaN}$ & $\mathrm{NaN}$ & $\mathrm{NaN}$ & $\mathrm{NaN}$ & $\mathrm{NaN}$ & $\mathrm{NaN}$ & $\mathrm{NaN}$ & $2.7599 \mathrm{E}+07$ & $2.0883 \mathrm{E}+07$ \\
\hline 2018-12-24 11:44:46 & $6.4095 \mathrm{E}+07$ & 358.6 & $6.0583 \mathrm{E}+07$ & 358.7 & $5.6851 \mathrm{E}+07$ & 358.8 & $5.6030 \mathrm{E}+07$ & 359.0 & $3.7900 \mathrm{E}+07$ & 362.3 & $3.0009 \mathrm{E}+07$ & $2.2534 \mathrm{E}+07$ \\
\hline NOAA-17/HIRS3 & 4.575 & & 4.523 & & 4.478 & & 4.464 & & 4.138 & & 3.970 & 3.763 \\
\hline 2003-01-24 01:20:02 & $1.9038 \mathrm{E}+07$ & 314.8 & $1.7845 \mathrm{E}+07$ & 315.3 & $1.6969 \mathrm{E}+07$ & 316.0 & $1.6659 \mathrm{E}+07$ & 316.1 & $1.1227 \mathrm{E}+07$ & 321.4 & $8.9445 \mathrm{E}+06$ & $6.7361 \mathrm{E}+06$ \\
\hline 2002-09-26 07:01:22 & $3.6261 \mathrm{E}+07$ & 336.5 & $3.3903 \mathrm{E}+07$ & 336.7 & $3.2094 \mathrm{E}+07$ & 337.1 & $3.1419 \mathrm{E}+07$ & 337.1 & $2.0808 \mathrm{E}+07$ & 340.8 & $1.6245 \mathrm{E}+07$ & $1.2074 \mathrm{E}+07$ \\
\hline NOAA-18/HIRS4 & 4.568 & & 4.528 & & 4.468 & & 4.451 & & 4.134 & & 3.975 & 3.751 \\
\hline 2018-11-26 17:59:54 & $4.6002 \mathrm{E}+07$ & 345.7 & $\mathrm{NaN}$ & $\mathrm{NaN}$ & $\mathrm{NaN}$ & $\mathrm{NaN}$ & $\mathrm{NaN}$ & $\mathrm{NaN}$ & $2.5536 \mathrm{E}+07$ & 348.0 & $2.0359 \mathrm{E}+07$ & $1.4623 \mathrm{E}+07$ \\
\hline 2018-04-02 09:27:54 & $\mathrm{NaN}$ & $\mathrm{NaN}$ & $\mathrm{NaN}$ & $\mathrm{NaN}$ & $\mathrm{NaN}$ & $\mathrm{NaN}$ & $\mathrm{NaN}$ & $\mathrm{NaN}$ & $3.5377 \mathrm{E}+07$ & 359.8 & $2.8333 \mathrm{E}+07$ & $2.0688 \mathrm{E}+07$ \\
\hline 2011-03-14 10:32:05 & $2.0236 \mathrm{E}+07$ & 317.1 & $1.9064 \mathrm{E}+07$ & 317.1 & $1.7484 \mathrm{E}+07$ & 317.4 & $1.7137 \mathrm{E}+07$ & 317.6 & $1.1122 \mathrm{E}+07$ & 321.3 & $8.9085 E+06$ & $6.4512 \mathrm{E}+06$ \\
\hline NOAA-19/HIRS4 & nan & & nan & & nan & & nan & & 4.131 & & 3.971 & 3.757 \\
\hline 2017-12-02 12:50:03 & $\mathrm{NaN}$ & $\mathrm{NaN}$ & $\mathrm{NaN}$ & $\mathrm{NaN}$ & $\mathrm{NaN}$ & $\mathrm{NaN}$ & $\mathrm{NaN}$ & $\mathrm{NaN}$ & $3.8682 \mathrm{E}+07$ & 363.3 & $3.1112 \mathrm{E}+07$ & $2.3276 \mathrm{E}+07$ \\
\hline 2012-03-04 05:07:04 & $\mathrm{NaN}$ & $\mathrm{NaN}$ & $\mathrm{NaN}$ & $\mathrm{NaN}$ & $\mathrm{NaN}$ & $\mathrm{NaN}$ & $\mathrm{NaN}$ & $\mathrm{NaN}$ & $\mathrm{NaN}$ & $\mathrm{NaN}$ & $1.3562 \mathrm{E}+07$ & $9.9920 \mathrm{E}+06$ \\
\hline MetOp-A/HIRS4 & 4.567 & & 4.520 & & 4.469 & & 4.453 & & 4.134 & & 3.974 & 3.754 \\
\hline 2011-11-16 23:42:26 & $2.3734 \mathrm{E}+07$ & 322.3 & $2.2566 \mathrm{E}+07$ & 323.0 & $2.0971 \mathrm{E}+07$ & 323.1 & $2.0538 \mathrm{E}+07$ & 323.3 & $1.3263 \mathrm{E}+07$ & 326.6 & $1.0328 \mathrm{E}+07$ & $7.6021 \mathrm{E}+06$ \\
\hline MetOp-B/HIRS4 & 4.575 & & 4.532 & & 4.476 & & 4.458 & & 4.130 & & 3.975 & 3.753 \\
\hline 2019-07-21 07:57:26 & $4.0649 \mathrm{E}+07$ & 340.7 & $3.7884 \mathrm{E}+07$ & 340.3 & $3.5236 \mathrm{E}+07$ & 340.5 & $3.4523 \mathrm{E}+07$ & 340.7 & $2.2187 \mathrm{E}+07$ & 343.5 & $1.7703 \mathrm{E}+07$ & $1.2787 \mathrm{E}+07$ \\
\hline 2015-02-07 05:12:40 & $\mathrm{NaN}$ & $\mathrm{NaN}$ & $5.5484 \mathrm{E}+07$ & 354.8 & $5.1837 \mathrm{E}+07$ & 355.1 & $5.0795 \mathrm{E}+07$ & 355.2 & $3.3225 \mathrm{E}+07$ & 357.7 & $2.6680 \mathrm{E}+07$ & $1.9463 \mathrm{E}+07$ \\
\hline
\end{tabular}

Notes. No brightness temperatures were determined for channels 17 and 18 due to the unknown contribution of reflected sunlight. 


\section{A.2. Moon full-disk flux densities}

Table A.4. Extracted disk-integrated fluxes of the Moon for the long-wavelength channels 1-12.

\begin{tabular}{|c|c|c|c|c|c|c|c|c|c|c|c|c|}
\hline $\begin{array}{l}\text { Satellite/Instrument } \\
\text { Observation epoch }\end{array}$ & $\begin{array}{r}\lambda_{\mathrm{ch} 01} \\
\mathrm{flx}_{1} \\
\end{array}$ & $\begin{array}{r}\lambda_{\mathrm{ch} 02} \\
\mathrm{flx}_{2} \\
\end{array}$ & $\begin{array}{r}\lambda_{\mathrm{ch} 03} \\
\mathrm{flx}_{3} \\
\end{array}$ & $\begin{array}{r}\lambda_{\mathrm{ch} 04} \\
\mathrm{flx}_{4} \\
\end{array}$ & $\begin{array}{r}\lambda_{\mathrm{ch} 05} \\
\mathrm{flx}_{5} \\
\end{array}$ & $\begin{array}{r}\lambda_{\mathrm{ch} 06} \\
\mathrm{flx}_{6} \\
\end{array}$ & $\begin{array}{r}\lambda_{\mathrm{ch} 07} \\
\mathrm{flx}_{7} \\
\end{array}$ & $\begin{array}{r}\lambda_{\mathrm{ch} 08} \\
\mathrm{flx}_{8} \\
\end{array}$ & $\begin{array}{r}\lambda_{\mathrm{ch} 09} \\
\mathrm{flx}_{9} \\
\end{array}$ & $\begin{array}{r}\lambda_{\mathrm{ch} 10} \\
\mathrm{flx}_{10} \\
\end{array}$ & $\begin{array}{r}\lambda_{\mathrm{ch} 11} \\
\mathrm{flx}_{11} \\
\end{array}$ & $\begin{array}{r}\lambda_{\mathrm{ch} 12}[\mu \mathrm{m}] \\
\mathrm{flx}_{12}[\mathrm{Jy}] \\
\end{array}$ \\
\hline NOAA-11/HIRS2 & 14.852 & 14.731 & 14.488 & 14.183 & 13.909 & 13.658 & 13.340 & 11.088 & 9.733 & 12.565 & 7.362 & 6.738 \\
\hline 1993-11-25 17:39 & $12 \mathrm{E}+10$ & $124 \mathrm{E}+10$ & $120 \mathrm{E}+10$ & $071 \mathrm{E}+10$ & $008 \mathrm{E}+10$ & $007 \mathrm{E}+10$ & $004 \mathrm{E}+10$ & $615 \mathrm{E}+10$ & $251 \mathrm{E}+10$ & $.897 \mathrm{E}+10$ & $842 \mathrm{E}+10$ & $399 \mathrm{E}+10$ \\
\hline 1992-02-15 19:54 & $388 \mathrm{E}+10$ & $5.565 \mathrm{E}+10$ & $584 \mathrm{E}+10$ & $505 \mathrm{E}+10$ & $433 E+10$ & $5.462 \mathrm{E}+10$ & $439 \mathrm{E}+10$ & $4.964 \mathrm{E}+10$ & $472 \mathrm{E}+10$ & $.326 \mathrm{E}+10$ & $2.540 \mathrm{E}+10$ & $1.929 \mathrm{E}+10$ \\
\hline 1990-11-27 05:04 & $2.659 \mathrm{E}+10$ & $2.703 E+10$ & $2.742 \mathrm{E}+10$ & $2.677 \mathrm{E}+10$ & $2.645 \mathrm{E}+10$ & $2.632 \mathrm{E}+10$ & $2.624 \mathrm{E}+10$ & $2.299 \mathrm{E}+10$ & $2.017 \mathrm{E}+10$ & $2.537 \mathrm{E}+10$ & $1.103 E+10$ & $8.137 \mathrm{E}+09$ \\
\hline 1989-03-17 03:31 & $995 \mathrm{E}+10$ & $137 \mathrm{E}+10$ & $194 \mathrm{E}+10$ & $.160 \mathrm{E}+10$ & $125 \mathrm{E}+10$ & $3.133 \mathrm{E}+10$ & $3.111 \mathrm{E}+10$ & $.798 \mathrm{E}+10$ & $2.484 \mathrm{E}+10$ & $.034 \mathrm{E}+10$ & $1.377 \mathrm{E}+10$ & $.028 \mathrm{E}+10$ \\
\hline IRS2 & 14.955 & 14.701 & 14.487 & 14.171 & 13.931 & 13.656 & 13.317 & 11.119 & 9.725 & 12.508 & 7.398 & 6.733 \\
\hline 2000-04-14 10:50 & $663 \mathrm{E}+10$ & $698 \mathrm{E}+10$ & $708 \mathrm{E}+10$ & $704 \mathrm{E}+10$ & $725 \mathrm{E}+10$ & $712 \mathrm{E}+10$ & $685 \mathrm{E}+10$ & $256 \mathrm{E}+10$ & $808 \mathrm{E}+10$ & $3.566 \mathrm{E}+10$ & $1.648 \mathrm{E}+10$ & $30 \mathrm{E}+10$ \\
\hline 1997-12-08 21:52 & $2.841 \mathrm{E}+10$ & $2.873 \mathrm{E}+10$ & $2.898 \mathrm{E}+10$ & $2.879 \mathrm{E}+10$ & $2.900 \mathrm{E}+10$ & $2.897 \mathrm{E}+10$ & $2.876 \mathrm{E}+10$ & $2.518 \mathrm{E}+10$ & $2.156 \mathrm{E}+10$ & $2.776 \mathrm{E}+10$ & $1.249 \mathrm{E}+10$ & $9.223 \mathrm{E}+09$ \\
\hline 1997-06-15 05:05 & $2.195 \mathrm{E}+10$ & $2.316 \mathrm{E}+10$ & $2.356 \mathrm{E}+10$ & $2.335 \mathrm{E}+10$ & $2.357 \mathrm{E}+10$ & $2.364 \mathrm{E}+10$ & $2.353 \mathrm{E}+10$ & $2.082 \mathrm{E}+10$ & $1.785 \mathrm{E}+10$ & $2.281 \mathrm{E}+10$ & $1.006 \mathrm{E}+10$ & $7.356 \mathrm{E}+09$ \\
\hline $0-2300: 30$ & $80 \mathrm{E}+10$ & $4.343 \mathrm{E}+10$ & & & & & & & & & +10 & $84 \mathrm{E}+10$ \\
\hline 1996-05-28 20:58 & $3.653 \mathrm{E}+10$ & $3.516 \mathrm{E}+10$ & $3.509 \mathrm{E}+10$ & $3.502 \mathrm{E}+10$ & $3.517 \mathrm{E}+10$ & $3.510 \mathrm{E}+10$ & $3.449 \mathrm{E}+10$ & $3.078 \mathrm{E}+10$ & $2.686 \mathrm{E}+10$ & $3.335 \mathrm{E}+10$ & $1.531 \mathrm{E}+10$ & $1.134 \mathrm{E}+10$ \\
\hline 1995-12-03 07:13 & $162 \mathrm{E}+10$ & $195 E+10$ & $4.253 \mathrm{E}+10$ & $4.257 \mathrm{E}+10$ & $4.287 \mathrm{E}+10$ & $4.296 \mathrm{E}+10$ & $4.276 \mathrm{E}+10$ & $3.870 \mathrm{E}+10$ & $3.395 \mathrm{E}+10$ & $4.173 \mathrm{E}+10$ & $2.021 \mathrm{E}+10$ & $.518 \mathrm{E}+10$ \\
\hline 15/HIRS3 & 14.976 & 14.743 & 14.508 & 14.226 & 13.963 & 13.666 & 13.357 & 11.151 & 9.705 & 12.444 & 7.303 & 6.534 \\
\hline 2019-12-14 09:47 & NAN & NAN & NAN & NAN & NAN & NAN & NAN & NAN & NAN & NAN & NAN & NAN \\
\hline 2018-12-24 11:44 & $5.708 \mathrm{E}+10$ & $5.757 \mathrm{E}+10$ & $5.757 \mathrm{E}+10$ & $5.774 \mathrm{E}+10$ & $5.797 \mathrm{E}+10$ & $5.802 \mathrm{E}+10$ & $5.748 \mathrm{E}+10$ & $5.367 \mathrm{E}+10$ & $4.420 \mathrm{E}+10$ & $5.707 \mathrm{E}+10$ & $2.628 \mathrm{E}+10$ & $1.921 \mathrm{E}+10$ \\
\hline NOAA-17/HIRS3 & 14.966 & 14.669 & 14.474 & 14.219 & 13.958 & 13.664 & 13.360 & 11.123 & 9.722 & 12.430 & 7.320 & 6.547 \\
\hline 2003-01-24 01:19 & $2.385 \mathrm{E}+10$ & $2.445 \mathrm{E}+10$ & $2.438 \mathrm{E}+10$ & $2.478 \mathrm{E}+10$ & $2.460 \mathrm{E}+10$ & $2.459 \mathrm{E}+10$ & $2.414 \mathrm{E}+10$ & $.115 \mathrm{E}+10$ & $1.683 \mathrm{E}+10$ & $2.358 \mathrm{E}+10$ & $9.439 \mathrm{E}+09$ & $6.543 \mathrm{E}+09$ \\
\hline 2002-09-26 07:01 & $2.853 \mathrm{E}+10$ & $2.976 \mathrm{E}+10$ & $3.036 \mathrm{E}+10$ & $3.090 \mathrm{E}+10$ & $3.109 \mathrm{E}+10$ & $3.151 \mathrm{E}+10$ & $3.148 \mathrm{E}+10$ & $2.932 \mathrm{E}+10$ & $2.443 \mathrm{E}+10$ & $3.124 \mathrm{E}+10$ & $1.385 \mathrm{E}+10$ & $9.738 \mathrm{E}+09$ \\
\hline HIRS4 & 14.980 & 14.697 & 14.513 & 14.223 & 14.006 & 13.670 & 13.340 & 11.117 & 9.720 & 12.501 & 7.314 & 6.513 \\
\hline 2018-11-26 17:59 & $25 \mathrm{E}+10$ & $11 \mathrm{E}+10$ & $32 \mathrm{E}+10$ & $24 \mathrm{E}+10$ & $317 \mathrm{E}+10$ & $314 \mathrm{E}+10$ & $320 \mathrm{E}+10$ & $965 \mathrm{E}+10$ & $E+10$ & $255 \mathrm{E}+10$ & $13 E+10$ & $06 \mathrm{E}+10$ \\
\hline 2018-04-02 09:27 & $4.911 \mathrm{E}+10$ & $4.985 \mathrm{E}+10$ & $4.997 \mathrm{E}+10$ & $4.991 \mathrm{E}+10$ & $4.988 \mathrm{E}+10$ & $5.002 \mathrm{E}+10$ & $5.030 \mathrm{E}+10$ & $4.650 \mathrm{E}+10$ & $4.150 \mathrm{E}+10$ & $4.960 \mathrm{E}+10$ & $2.385 \mathrm{E}+10$ & $1.660 \mathrm{E}+10$ \\
\hline 2011-03-14 10:32 & $2.413 \mathrm{E}+10$ & $2.399 \mathrm{E}+10$ & $2.399 \mathrm{E}+10$ & $2.385 \mathrm{E}+10$ & $2.371 \mathrm{E}+10$ & $2.369 \mathrm{E}+10$ & $2.370 \mathrm{E}+10$ & $2.086 \mathrm{E}+10$ & $1.789 \mathrm{E}+10$ & $2.304 \mathrm{E}+10$ & $9.820 \mathrm{E}+09$ & $6.575 \mathrm{E}+09$ \\
\hline $\mathrm{NOA}$ & 14.953 & 14.685 & 14.526 & 14.232 & 13.973 & 13.635 & 13.347 & 11.124 & 9.729 & 12.456 & 7.352 & 6.529 \\
\hline 2017-12-02 12:49 & $311 \mathrm{E}+10$ & $6.316 \mathrm{E}+10$ & $6.316 \mathrm{E}+10$ & $6.286 \mathrm{E}+10$ & $6.273 E+10$ & $6.302 \mathrm{E}+10$ & $6.330 \mathrm{E}+10$ & $5.877 \mathrm{E}+10$ & $5.290 \mathrm{E}+10$ & $6.279 \mathrm{E}+10$ & $3.100 \mathrm{E}+10$ & $2.158 \mathrm{E}+10$ \\
\hline 2012-03-04 05:07 & NAN & NAN & NAN & NAN & NAN & NAN & NAN & NAN & NAN & NAN & NAN & NAN \\
\hline MetOp-A/HIRS4 & 14.955 & 14.719 & 14.503 & 14.248 & 13.955 & 13.667 & 13.354 & 11.129 & 9.723 & 12.486 & 7.343 & 6.536 \\
\hline 2011-11-16 23:42 & $2.407 \mathrm{E}+10$ & $2.428 \mathrm{E}+10$ & $2.439 \mathrm{E}+10$ & $2.435 \mathrm{E}+10$ & $2.442 \mathrm{E}+10$ & $2.431 \mathrm{E}+10$ & $2.421 \mathrm{E}+10$ & $2.168 \mathrm{E}+10$ & $1.869 \mathrm{E}+10$ & $2.340 \mathrm{E}+10$ & $1.045 \mathrm{E}+10$ & $7.151 \mathrm{E}+09$ \\
\hline 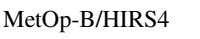 & 14.964 & 14.688 & $14.4 / 4$ & 14.248 & 13.996 & 13.671 & 13.390 & 11.127 & 9.715 & 12.438 & 7.355 & 6.521 \\
\hline 2019-07-21 07:57 & $3.414 \mathrm{E}+10$ & $3.431 \mathrm{E}+10$ & $3.414 \mathrm{E}+10$ & $3.407 \mathrm{E}+10$ & $3.384 \mathrm{E}+10$ & $3.378 \mathrm{E}+10$ & $3.387 \mathrm{E}+10$ & $3.046 \mathrm{E}+10$ & $2.677 \mathrm{E}+10$ & $3.316 \mathrm{E}+10$ & $1.515 \mathrm{E}+10$ & $1.042 \mathrm{E}+10$ \\
\hline 2015-02-07 05:12 & $4.396 \mathrm{E}+10$ & $4.382 \mathrm{E}+10$ & $4.386 \mathrm{E}+10$ & $4.377 \mathrm{E}+10$ & $4.354 \mathrm{E}+10$ & $4.354 \mathrm{E}+10$ & $4.369 \mathrm{E}+10$ & $3.989 \mathrm{E}+10$ & $3.558 \mathrm{E}+10$ & $4.303 \mathrm{E}+10$ & $2.060 \mathrm{E}+10$ & $1.446 \mathrm{E}+10$ \\
\hline
\end{tabular}


T. G. Müller et al.: Benchmarking the asteroid TPM against the Moon

Table A.5. Extracted disk-integrated fluxes of the Moon for the short-wavelength channels 13-19.

\begin{tabular}{|c|c|c|c|c|c|c|c|}
\hline $\begin{array}{l}\text { Satellite/Instrument } \\
\text { Observation epoch }\end{array}$ & $\begin{array}{r}\lambda_{\mathrm{ch} 13} \\
\mathrm{flx}_{13} \\
\end{array}$ & $\begin{array}{r}\lambda_{\mathrm{ch} 14} \\
\mathrm{flx}_{14} \\
\end{array}$ & $\begin{array}{r}\lambda_{\mathrm{ch} 15} \\
\mathrm{flx}_{15} \\
\end{array}$ & $\begin{array}{r}\lambda_{\operatorname{ch} 16} \\
\operatorname{flx}_{16} \\
\end{array}$ & $\begin{array}{r}\lambda_{\mathrm{ch} 17} \\
\mathrm{flx}_{17} \\
\end{array}$ & $\begin{array}{r}\lambda_{\mathrm{ch} 18} \\
\mathrm{flx}_{18} \\
\end{array}$ & $\begin{array}{r}\lambda_{\mathrm{ch} 19}[\mu \mathrm{m}] \\
\mathrm{flx}_{19}[\mathrm{Jy}] \\
\end{array}$ \\
\hline NOAA-11/HIRS2 & 4.566 & 4.525 & 4.466 & 4.409 & 4.138 & 3.981 & 3.753 \\
\hline $1993-11-25$ 17:39 & $2.552 \mathrm{E}+09$ & $2.417 \mathrm{E}+09$ & $2.257 \mathrm{E}+09$ & $2.125 E+09$ & $1.502 \mathrm{E}+09$ & $1.232 \mathrm{E}+09$ & $9.029 \mathrm{E}+08$ \\
\hline 1992-02-15 19:54 & NAN & NAN & NAN & NAN & $2.053 \mathrm{E}+09$ & NAN & NAN \\
\hline 1990-11-27 05:04 & NAN & NAN & NAN & NAN & $7.640 \mathrm{E}+08$ & NAN & NAN \\
\hline 1989-03-17 03:31 & NAN & NAN & NAN & NAN & $9.814 \mathrm{E}+08$ & NAN & NAN \\
\hline NOAA-14/HIRS2 & 4.563 & 4.530 & 4.472 & 4.409 & 4.132 & 3.980 & 3.776 \\
\hline $2000-04-14$ 10:50 & $2.117 \mathrm{E}+09$ & $2.029 \mathrm{E}+09$ & $1.883 \mathrm{E}+09$ & $1.741 \mathrm{E}+09$ & $1.189 \mathrm{E}+09$ & $9.726 \mathrm{E}+08$ & $7.257 \mathrm{E}+08$ \\
\hline 1997-12-08 21:52 & $1.535 \mathrm{E}+09$ & $1.470 \mathrm{E}+09$ & $1.365 \mathrm{E}+09$ & $1.259 \mathrm{E}+09$ & $8.590 \mathrm{E}+08$ & $7.023 \mathrm{E}+08$ & $5.238 \mathrm{E}+08$ \\
\hline 1997-06-15 05:05 & $1.163 \mathrm{E}+09$ & $1.122 \mathrm{E}+09$ & $1.040 \mathrm{E}+09$ & $9.605 \mathrm{E}+08$ & $6.616 \mathrm{E}+08$ & $5.418 \mathrm{E}+08$ & $4.055 \mathrm{E}+08$ \\
\hline 1996-10-23 00:30 & $2.642 \mathrm{E}+09$ & $2.545 \mathrm{E}+09$ & $2.367 \mathrm{E}+09$ & $2.194 \mathrm{E}+09$ & $1.525 \mathrm{E}+09$ & $1.255 \mathrm{E}+09$ & $9.431 \mathrm{E}+08$ \\
\hline $1996-05-2820: 58$ & $1.949 \mathrm{E}+09$ & $1.878 \mathrm{E}+09$ & $1.749 \mathrm{E}+09$ & $1.620 \mathrm{E}+09$ & $1.134 \mathrm{E}+09$ & $9.350 \mathrm{E}+08$ & $7.067 \mathrm{E}+08$ \\
\hline 1995-12-03 07:13 & $2.747 \mathrm{E}+09$ & $2.641 \mathrm{E}+09$ & $2.456 \mathrm{E}+09$ & $2.272 \mathrm{E}+09$ & $1.568 \mathrm{E}+09$ & $1.287 \mathrm{E}+09$ & $9.642 \mathrm{E}+08$ \\
\hline NOAA-15/HIRS3 & 4.570 & 4.525 & 4.474 & 4.460 & 4.134 & 3.970 & 3.763 \\
\hline 2019-12-14 09:47 & NAN & NAN & NAN & NAN & NAN & $1.832 \mathrm{E}+09$ & $1.386 \mathrm{E}+09$ \\
\hline 2018-12-24 11:44 & $4.603 E+09$ & $4.351 \mathrm{E}+09$ & $4.083 E+09$ & $4.024 \mathrm{E}+09$ & $2.722 \mathrm{E}+09$ & $2.155 \mathrm{E}+09$ & $1.618 \mathrm{E}+09$ \\
\hline NOAA-17/HIRS3 & 4.575 & 4.523 & 4.478 & 4.464 & 4.138 & 3.970 & 3.763 \\
\hline 2003-01-24 01:19 & $1.305 E+09$ & $1.223 \mathrm{E}+09$ & $1.163 \mathrm{E}+09$ & $1.142 \mathrm{E}+09$ & $7.696 \mathrm{E}+08$ & $6.131 \mathrm{E}+08$ & 4.617E+08 \\
\hline 2002-09-26 07:01 & $2.103 E+09$ & $1.966 \mathrm{E}+09$ & $1.862 \mathrm{E}+09$ & $1.822 \mathrm{E}+09$ & $1.207 \mathrm{E}+09$ & $9.422 \mathrm{E}+08$ & $7.003 \mathrm{E}+08$ \\
\hline NOAA-18/HIRS4 & 4.568 & 4.528 & 4.468 & 4.451 & 4.134 & 3.975 & 3.751 \\
\hline $2018-11-26$ 17:59 & $3.205 \mathrm{E}+09$ & NAN & NAN & NAN & $1.779 \mathrm{E}+09$ & $1.419 \mathrm{E}+09$ & $1.019 \mathrm{E}+09$ \\
\hline 2018-04-02 09:27 & NAN & NAN & NAN & NAN & $2.219 \mathrm{E}+09$ & $1.777 \mathrm{E}+09$ & $1.297 \mathrm{E}+09$ \\
\hline 2011-03-14 10:32 & $1.321 \mathrm{E}+09$ & $1.244 \mathrm{E}+09$ & $1.141 \mathrm{E}+09$ & $1.118 \mathrm{E}+09$ & $7.259 \mathrm{E}+08$ & $5.814 \mathrm{E}+08$ & $4.210 \mathrm{E}+08$ \\
\hline NOAA-19/HIRS4 & nan & nan & nan & nan & 4.131 & 3.971 & 3.757 \\
\hline 2017-12-02 12:49 & NAN & NAN & NAN & NAN & $2.783 \mathrm{E}+09$ & $2.238 \mathrm{E}+09$ & $1.674 \mathrm{E}+09$ \\
\hline 2012-03-04 05:07 & NAN & NAN & NAN & NAN & NAN & $8.511 \mathrm{E}+08$ & $6.270 \mathrm{E}+08$ \\
\hline MetOp-A/HIRS4 & 4.567 & 4.520 & 4.469 & 4.453 & 4.134 & 3.974 & 3.754 \\
\hline $2011-11-1623: 42$ & $1.497 \mathrm{E}+09$ & $1.423 \mathrm{E}+09$ & $1.323 \mathrm{E}+09$ & $1.295 \mathrm{E}+09$ & $8.365 \mathrm{E}+08$ & $6.514 \mathrm{E}+08$ & $4.795 \mathrm{E}+08$ \\
\hline MetOp-B/HIRS4 & 4.575 & 4.532 & 4.476 & 4.458 & 4.130 & 3.975 & 3.753 \\
\hline 2019-07-21 07:57 & $2.319 \mathrm{E}+09$ & $2.161 \mathrm{E}+09$ & $2.010 \mathrm{E}+09$ & $1.970 \mathrm{E}+09$ & $1.266 \mathrm{E}+09$ & $1.010 \mathrm{E}+09$ & $7.295 \mathrm{E}+08$ \\
\hline 2015-02-07 05:12 & NAN & $3.160 \mathrm{E}+09$ & $2.953 \mathrm{E}+09$ & $2.893 \mathrm{E}+09$ & $1.892 \mathrm{E}+09$ & $1.520 \mathrm{E}+09$ & $1.109 \mathrm{E}+09$ \\
\hline
\end{tabular}

